\title{
New Insights on Folliculogenesis and Follicular Placentation in Marine Viviparous Fish Black Rockfish (Sebastes Schlegelii)
}

\section{Xiaojie Xu}

IOCAS: Institute of Oceanology Chinese Academy of Sciences

Qinghua Liu ( $\square$ qinghualiu@qdio.ac.cn )

IOCAS: Institute of Oceanology Chinese Academy of Sciences https://orcid.org/0000-0003-4726-5797

\section{Xueying Wang}

IOCAS: Institute of Oceanology Chinese Academy of Sciences

\section{Xin Qi}

Ocean University of China

\section{Li Zhou}

IOCAS: Institute of Oceanology Chinese Academy of Sciences

\section{Haoming Liu}

Fisheries Research Institute

Jun Li

IOCAS: Institute of Oceanology Chinese Academy of Sciences

\section{Research Article}

Keywords: Folliculogenesis, Follicular placentation, Viviparous fish, Sebastes schlegelii

Posted Date: June 7th, 2021

DOl: https://doi.org/10.21203/rs.3.rs-498317/v1

License: (c) (i) This work is licensed under a Creative Commons Attribution 4.0 International License.

Read Full License

Version of Record: A version of this preprint was published at Gene on April 1st, 2022. See the published version at https://doi.org/10.1016/j.gene.2022.146444. 
1 New insights on folliculogenesis and follicular placentation in marine viviparous fish

2 black rockfish (Sebastes schlegelii)

3 Xiaojie $\mathrm{Xu}^{1,3, \mathrm{a}}$,Qinghua $\mathrm{Liu}^{1,2, \mathrm{a}^{*}}$, Xueying Wang ${ }^{1,2}$, Xin $\mathrm{Qi}^{4}$, Li Zhou ${ }^{1,3}$, Haoming

$4 \mathrm{Liu}^{5,6}$, Jun $\mathrm{Li}^{1,2^{*}}$

5 *For correspondence: Qinghua Liu, qinghualiu@qdio.ac.cn; Jun Li, junli@qdio.ac.cn

6 Abstract:

7 Background: In viviparous fish, a considerable degree of variation in placental

8 structures have been described. However, no distinct structures are reported in 9 Scorpaenidae.

10 Results: In this study, we demonstrate a new type of folliculogenesis and follicular 11 placentation in Sebastes schlegelii. Before copulation, the germinal epithelium gradually surrounds the oocytes and develops to individually follicles with a stalk-like structure hanging on the ovigerous lamella, which ensures each follicle have access to spermatozoa after copulation. From stage V to early gestation, the cyp17-I highly expressed accompanied by cyp19ala signals disappearance, and 11-ketotestosterone level keeps rising and peaks at blastula stage, while 17ß-estradiol declines to the bottom. Meanwhile, the theca cells rapidly proliferate and invade outwards forming a highly hypertrophied and folded microvillous placenta. This unbalance of hormone might be an important factor driving the theca cells proliferation and invasion. Additionally, some conserved genes related to mammalian placentation are significantly high expression in follicular placenta suggesting the high convergence in vertebrate placenta evolution.

Conclusions: This finding provided a new type of placentation pattern for viviparous teleost between the intrafollicular gestation and intraluminal gestation.

Key words: Folliculogenesis, Follicular placentation, Viviparous fish, Sebastes schlegelii 


\section{Background}

33 Viviparity reproduction is a wide-spread reproductive strategy [1]. It earliest arose among fishes, and it occurred in most vertebrates, including most cartilaginous fishes, several clades of bony fishes, amphibians, reptiles and most mammals $[2,3,4]$. The developing embryos were retained within the parental body, supported by its own reserved yolk or provision of maternally derived nutrients, and leaded to release of live offspring instead of egg. Over 500 species of teleost fish in 14 families have been identified as viviparity $[5,6]$.

For viviparity, initial steps in the evolution of live-bearing from egg-laying must involve a shift from external to internal fertilization. The male transferred the sperm to the female gonaduct and fertilized the eggs [7,8]. Therefore, morphological and physiological adaptations of the ovary to facilitate the maternal-embryo interaction is an obligatory aspect of viviparity [9]. In fish, since the first "follicular pseudoplacenta" or a placental analogs in poeciliidae was described [10,11], a considerable degree of variation in placental structures were reported, including umbilical cord in shark [12], brood pouch of the male in sygnathid $[13,14]$ or the ovarian gestation in Zoarcidae [15], Cyprinodontiformes and Sebastinae [6, 8, 11, 16]. Intraovarian gestation is unique among vertebrates $[17,18]$, for lacking Mullerian ducts from which oviducts develop in other vertebrates $[19,20,21]$.

Placenta is a transient organ to facilitate the nutrition, gases and waste exchange and to regulate maternal-fetal interactions often through hormone production [22, 23]. The evolution of a novel organ typically involves both functional innovations and a novel structure which is associated with this function. In both Poeciliopsis retropinna and P. turneri $[8,17,24,25]$, the inner surface of the maternal follicular epithelium was highly hypertrophied and extensively folded $[8,26]$. In Goodeidnae, at mid to late gestation stages, the embryos moved from follicle to the ovarian lumen and developed a trophotaeniae. $[2,11,27]$

In Scorpaenidae, four genera (Sebastes, Sebasticus, Helicolenus and Hozukius) also belong to the marine viviparity [19], but no obviously developed structures were 
observed [28]. Black rockfish (Sebastes schlegelii) is an important comercial marine species which inhabits in North China, Korea, and Japan. The female and male copulate in November, while fertilization occurs in the next March. After almost 2 months of pregnancy in the ovary, the offspring are released into the sea [29, 30]. Usually, the enormous fecundity was diminished to adapt internal fertilization and gestation [31]. Interestingly, the fecundity of black rockfish is high and comparable to that of oviparous fishes ranging from 35,000 to 472,000 [32, 33, 34, 35, 36]. Therefore, it raises an intriguing question, how does the black rockfish modify the morphology, physiology and gene expression profile to adapt this reproductive strategy. In this study, we investigated the developmental process of oogenesis and gestation and found that the folliculogeneis of black rockfish is different from oviparous species and other documented viviparous placentas. When the oocytes developed to early secondary growth (SGe) stage, the follicles were surrounded by the germinal epithelium with stalk-like structures attached the ovigerous lamella. The results from in situ hybridization (ISH), steroid hormone changes and transcriptome indicated the dramatical expression of cytochrome P450c17 (cyp17-I) from full secondary growth (SGf) to blastula stage gave rise to the theca cells rapidly proliferation, migration and invasion into the stroma and formed a new type of follicular placenta. Additionally, the closely associated genes with mammalian placentation including HLA-E, laminin a4 (lama4), placenta special gene 8 (plac8), trophoblast glycoprotein (tpbg), placenta growth factor ( $p l g f$ ) expressed strongly throughout placentation suggesting these high conserved genes were convergent in the vertebrate placentation.

\section{Results}

\subsection{Oogenesis and gestation of Sebastes schlegelii}

Oogenesis and embryonic development of black rockfish are shown in figure1. For both black rockfish and turbot, the germinal epithelium bordered the various developing stage oocytes and formed the ovigerous lamella. But for black rockfish, it contained much more richer stroma in comparision with turbot (Fig. 1a-c). When the 
oocytes developed into the SGe stage, they were surrounded by the germinal epithelium, but still remained attaching to the stroma through a stalk-like structure. At this stage, the female and male copulated, and the male transferred spermatozoa to the ovarian cavity (Fig. 1c-c2). Numerous spermatozoa scattered in the ovarian lumen immediately after copulation, and stored in the crypt between the epithelium cells and theca layer or at the folds outside the follicles (Fig. 1d-e). At SGf stage, the vitellogenesis finished, oocytes entered into maturation and follicle layers broke down (Fig. 1f). Then the eggs fertilized with the spermatozoa which hidden in the crypt or folds before. At the same time, the granulosa detached from the zona pellucida (ZP), and mixed with the surrounding theca layers forming a barrier. After that, they rapidly migrated and invaded into the surrounding tissues and formed a follicular placenta to support the embryos development (Fig. 1g)
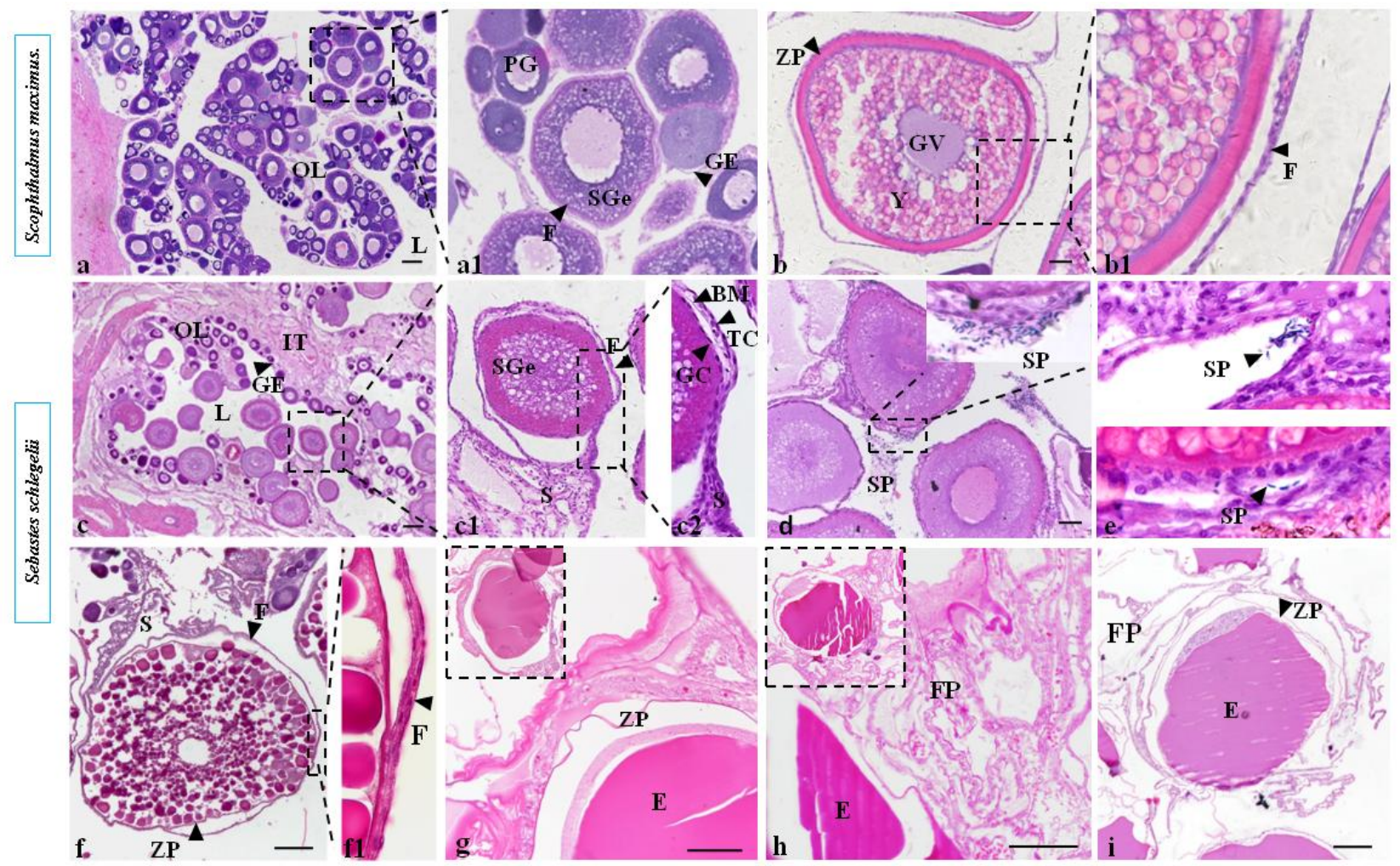

102

103 Figure 1. Oogenesis and embryonic development of black rockfish compared with

104 turbot. Numerous primary growth oocytes and early secondary growth (SGe) oocytes 105 surrounded by follicle cells in the stage III ovary of turbot (a, a1). Full secondary 106 growth (SGf) oocytes surrounded by a thick zona pellucida (ZP) and thin follicle cells $107(\mathrm{~F})$ in the stage $\mathrm{V}$ ovary of turbot $(\mathrm{b}, \mathrm{b} 1)$. Numerous primary growth oocytes and early 
secondary growth (SGe) oocytes surrounded by follicle cells in the stage III ovary of

109 black rockfish (c, c1). Numerous spermatozoa of scatter in the ovarian lumen outside 110 of the follicles in the stage III ovary of black rockfish (d, d1). Numerous spermatozoa 111 hide in the crypt of the stromal cells or the folds outside of the follicles in the stage IV 112 ovary of black rockfish (e). SGf oocytes are surround by a thin ZP and follicular 113 layers in the stage V ovary of black rockfish (f). At cleavage stage, the granulosa cells 114 have detached from the oocyte and the follicular layers (granulosa layer, theca layer 115 and basement membrane ) mixed with the surrounding epithelium and stroma cells 116 and formed follicular placenta (g). Follicular placenta structure became highly 117 hypertrophied, extensively folded at blastula stage (h). Follicular placenta became 118 more loose at gastrulae stage (i). L, lumen; OL, ovigerous lamella; IT, intersticial 119 tissue; PG, follicles with primary growth; GE, germinal epithelium; TC, theca cells; 120 GC, granulosa cells; BM, basement membrane; YG, yolk globule; BV, blood vessel; 121 ZP, zona pellucida; S, stroma; SGf, full secondary growth; SGe, early secondary 122 growth; F, follicle layers; FP, follicular placenta; E, embryo. Scale bars, $200 \mu \mathrm{m}$

\section{$123 \quad 2.2$ Characterization of $\boldsymbol{H L A}-\boldsymbol{E}$}

124 The open-reading frame of black rockfish $H L A-E$ is $1170 \mathrm{bp}$. The deduced HLA-E 125 protein is composed of 389 amino acids. The results of conserved domain showed that 126 black rockfish had the same conserved domains as humans (Fig. 2a). Since HLA-E 127 belongs to the major histocompatibility complex class I family (MHC-I), the 128 phylogenetic analysis was conducted using the predicted amino acid sequences to 129 analyze the evolutionary relationship of the major histocompatibility complex 130 class I family (MHC-I). The MHC-I are divided into two main groups. Sebastes 131 schlegelii, Oplegnathus fasciatus, Perca flavescens, Epinephelus lanceolatus, Homo 132 sapiens and Pongo abelii clustered in one of the subbranches. These results showed 133 that HLA-E gene of Sebastes schlegelii was homologous to Homo sapiens (Fig. 2b) 
A

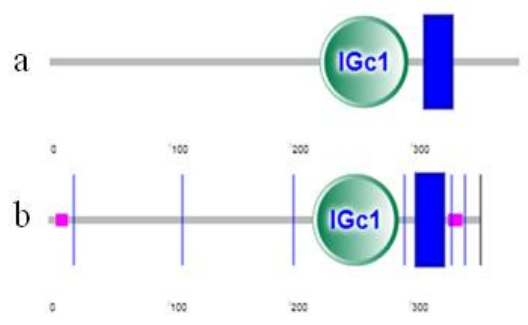

B

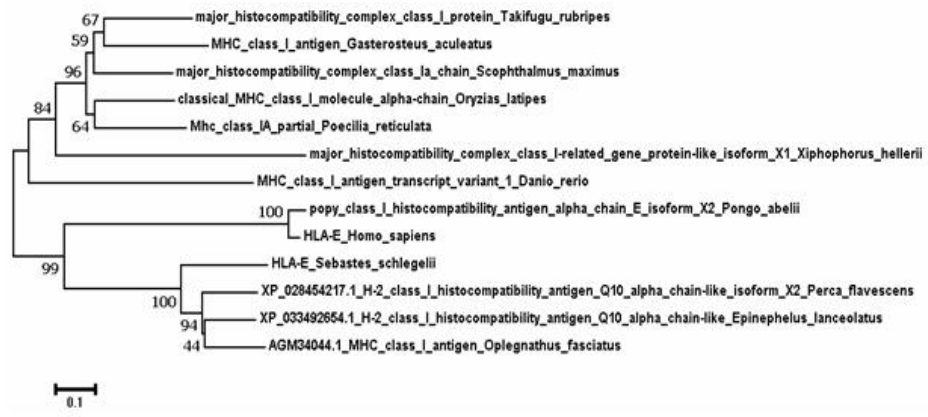

134

135

136 Figure 2. The conserved domains and phylogenetic tree of HLA-E in black rockfish

137 A. The HLA-E of black rockfish has the same conserved domains as humans.

138 Conserved domains of black rockfish (a). Conserved domains of human (b). B. The 139 phylogenetic tree of the major histocompatibility complexclass I family (MHC- I )

140 includes black rockfish and other vertebrates using predicted amino acid sequences.

141 The GenBank accession numbers are as follows: Xiphophorus macufulls H-2 class I

142 histocompatibility antigen, alpha chain-like (XP_023201134.1), Poecilia reticufull

143 PREDICTED: H-2 class I histocompatibility antigen, Q10 alpha chain-like isoform

144 X1 (XP_008420844.1), Homo sapiens HLA-E (ARB08449.1), Pongo abeliipopy

145 class I histocompatibility antigen, alpha chain E isoform X2 (XP_024104292.1),

146 Danio rerioMHC class I antigen transcript variant 1 (ALL98461.1), Gasterosteus 147 aculeatus MHC class I antigen (ABN14357.1), Scophthalmus maximusmajor 148 histocompatibility complex class Ia chain (ABM92962.1), Takifugu rubripes major 149 histocompatibility complex class I protein (AAC41236.1), Oryziaslatipes classical 150 MHC class I molecule, alpha-chain (BAJ07297.2), Oplegnathus fasciatus MHC class

151 I antigen (AGM34044.1), Perca flavescensH-2 class I histocompatibility antigen, Q10 152 alpha chain-like isoform X2 (XP_028454217.1), EpinepheluslanceolatusH-2 class I

153 histocompatibility antigen, Q10 alpha chain-like (XP_033492654.1).

154 2.3 The changes of hormone level and related genes expression during the 155 process of ovarian development. 
156 Two-cell type model illustrating the interaction of granulosa layers and theca cells of 157 the ovarian follicle in the biosynthesis of active steroid hormones in gonad are shown 158 in figure $3 \mathrm{~A}$. In vertebrates, granulosa and theca cells in the follicles are responsible 159 for the steroid hormone biosynthesis, including gonadal steroid hormones, 160 progesterone, estradiol [37, 38]. After cholesterol is catalyzed by the cholesterol 161 CYP11A1, pregnenolone and progesterone undergo 17a-hydroxylation and proceed 162 down the C21, 17-hydroxy pathway to 17a-hydroxypregnenolone and 163 17a-hydroxyprogesterone, respectively. CYP17 has17a-hydroxylase and 17,20-lyase 164 activity [39, 40], and only specifically expresses in the specific steroid-production 165 theca cells in the theca layers, which is critical not only for maintaining the structural 166 integrity of the follicle but also for delivering nutrients to the avascular granulosa cell layer. And the theca-derived androgens are then converted to estradiol by the CYP19A1 enzyme in granulosa cells.

The results of steroid hormone of black rockfish and turbot are shown in figure 3B, figure 3C, respectively. The 11-ketotestosterone (11-KT) had been at a low level until stage IV, then gradually rose and peaked at blastula stage, and remained at a relatively high level throughout the pregnancy. In the process of vitellogenesis, the level of

$17317 \beta$-estradiol $\left(\mathrm{E}_{2}\right)$ increased significantly and peaked at stage IV, then dramatically 174 decreased from stage $\mathrm{V}$ to blastula stage. During mid to late pregnancy, $\mathrm{E}_{2}$ also 175 maintained a high level, and peaked again during the gastrulae period. In the process 176 of oogenesis, the level of progesterone (P) was low, while the level of progesterone 177 rose rapidly and remained at a very high level at gestation stage (Fig. 3B). For turbot, 178 the level of $E_{2}$ presented an upward trend from stage II to stage IV, and decreased 179 from stage IV to stage $\mathrm{V}$. The change trend of progesterone and 11-KT were similar 180 to that of $\mathrm{E}_{2}$ (Fig. 3C).

181 The results of two-color fluorescence in situ hybridization of cyp17-I and cyp19ala 182 at SGf and blastula stage are shown in figure 3D. When the oocytes developed to SGf 183 stage, both cyp17-I with green signals and cyp19ala with red signals expressed on 184 theca cells and granulosa cells, respectively (Fig. 3a1-a3). However, when the embryo 185 developed to the blastula stage, only cyp17-I showed signals on follicular placenta, 186 and cyp19ala had no obvious signals (Fig. 3b1-b3). 
Expression profile of some important genes related to oogenesis and gestation at eight different stages are shown in figure 3E. For black rockfish luteinizing hormone/choriogonadotropin receptor (lhcgr), follicle stimulation hormone receptor $(f s h r)$, steroid acute regulatory protein (star), cholesterol side-chain cleavage enzyme

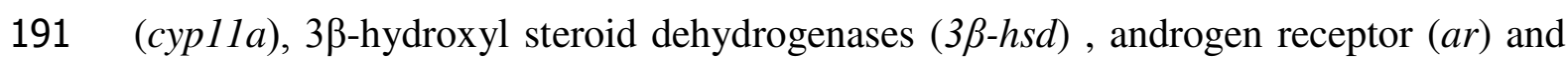
192 cytochrome P450 aromatase (cyp19ala) were highly expressed during oogenesis and 193 weakly expressed during pregnancy. During oogenesis, these genes had the same 194 expression trend in both black rockfish and turbot. The cyp17-I, progesterone receptor 195 (pgr), estrogen receptor alpher (era), estrogen receptor beta1 (erbl), estrogen receptor 196 beta2 (erb2), plac8, tpbg, plgf, HLA-E and lama4 strongly expressed during 197 pregnancy, especially plac8, tpbg and plgf in the early and mid pregnancy in black 198 rockfish. HLA-E, lama4, cyp19alb, plac8 and era were not detected in turbot.

A

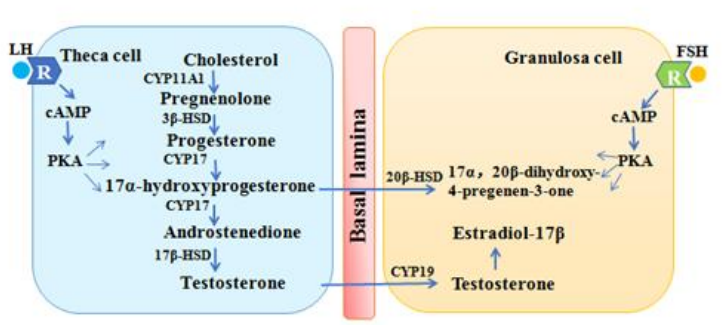

D

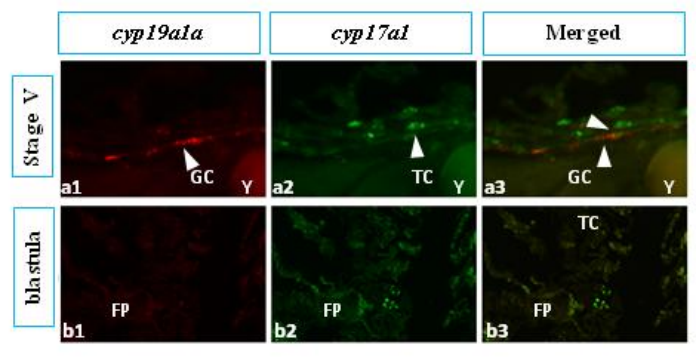

B
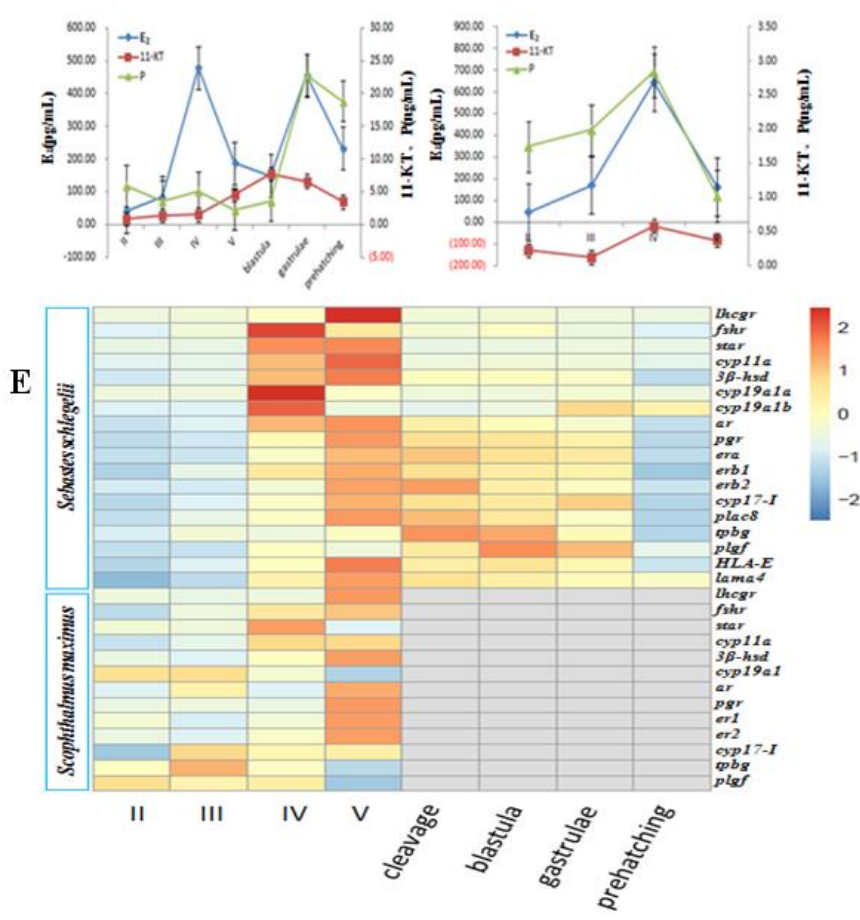

200 Figure 3. The changes of hormone level and related genes expression during the

201 process of the ovarian development. A. Two-cell type model illustrates the Interaction 202 of granulosa layers and theca cells of the ovarian follicle in the biosynthesis of active 203 steroid hormones in gonad. Enzymes: P450scc (CYP11A1), P450 side-chain cleavage; 
P450c17(CYP17), 17-hydroxylase/C17-C20-lyase; 3b-HSD, 3b-hydroxysteroid dehydrogenase;17b-HSD, 17b-hydroxysteroid dehydrogenase; 20b-HSD, 206 20b-hydroxysteroid dehydrogenase; P450arom (CYP19A), P450 aromatase. B. Three 207 steroid hormone changes during the oogenesis and placentation of black rockfish. 208 11-KT had been at a low level until the ovary developed to stage IV. When the ovary 209 developed to stage IV, 11-KT level gradually rose and peaked at blastula stage. After that, it decreased slightly but still remained at a relatively high level throughout the pregnancy. The level of $\mathrm{E}_{2}$ increased significantly from stage III to stage $\mathrm{V}$, and

212 decreased at blastula stage. During pregnancy, $\mathrm{E}_{2}$ also maintained a high level, and 213 peaked again during the gastrulae period. The level of $\mathrm{P}$ was low until blastula stage, 214 it rapidly rose and remained a high level during the pregnancy period. C. Three 215 steroid hormone changes during the oogenesis of turbot. The 11-KT, $\mathrm{E}_{2}$ and $\mathrm{P}$ level 216 presented an upward trend, peaked stage IV and decreased from stage IV to stage V. D. 217 The results of two-color fluorescence in situ hybridization of cyp17-I and cyp19ala at 218 SGf and blastula. The expression of cyp17-I with green and cyp19ala with red at SGf 219 of black rockfish (a1-a3). the expression of cyp17-I with green and cyp19ala with red 220 in blastula stage of black rockfish (b1-b3). E. Expression profile of some important 221 genes during ovarian development at eight different development stages. The log ratio 222 expression is indicated in a heat map. 11-KT, 11-ketotestosterone; $\mathrm{E}_{2}, 17 \beta$-estradiol; $\mathrm{P}$, 223 progesterone; TC, theca cells; GC, granulosa cells; Y, yolk granules; FP, follicular 224 placenta.

\subsection{Cyp17-I, cyp19a1a, fshr, lama4 and HLA-E mRNA location in gonad during}

\section{6 the oogenesis}

227 The expression of cyp17-I, cyp19ala, fshr, lama4 and HLA-E in gonad during 228 oogenesis are shown in figure 4 . When the oocytes developed to SGe stage, cyp 17-I

229 expressed on theca cells, and the signals gradually increased with the ovary 230 development. When the oocytes developed to SGf stage, the signals of cyp17-I could 231 be detected not only on theca cells, but throughout all the stromal cells around the 
oocytes, especially in stalk-like tissues (Fig. 4a1-a3). For cyp19ala, it only expressed on granulosa cells and the signals got much stronger from SGe to late secondary growth (SGl) stage, and became very weak at SGf stage (Fig. 4b1-b3). While $f$ shr signals presented similar position and change trend with cyp19ala (Fig. 4c1-c3). Lama4 signals could not be detected on theca cells until the oocytes developed to SGI stage, and significantly increased at SGf stage on theca cells as well as the stromal cells around the oocytes (Fig. 4d1-d3). Similarly, the signals of HLA-E expressed on theca cells and stromal cells around the oocytes, and gradually increased as the ovary developed (Fig. 4e1-e3).

For turbot, cyp17-I was also detected on theca cells, but the difference was that cyp17-I of turbot only expressed on theca cells, not on the stromal cells around the oocytes at SGf stage (Fig. 4a4). The expression of cyp19ala and fshr of turbot was similar to black rockfish that the signals expressed on granulosa cells (Fig. 4b4, c4). Lama4 had no signal at SGf stage, which was completely different from black rockfish during this period (Fig. 4d4).

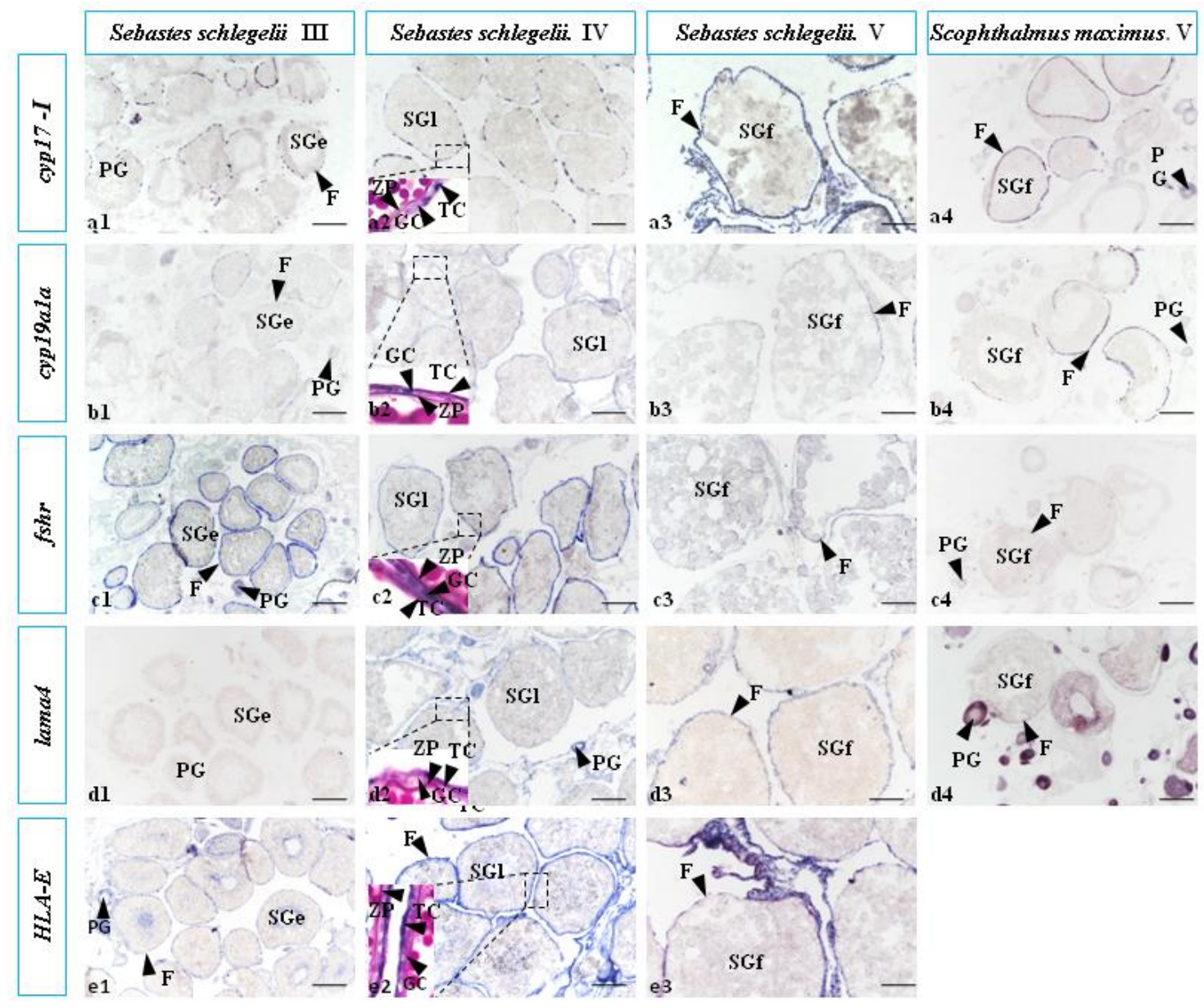


247 Figure 4. The expression of cyp17-I, cyp19ala, fshr, lama4 and HLA-E in gonad 248 during the oogenesis. At SGe stage, cyp17-I expressed on theca cells, and the signals 249 gradually increased with the ovary development. At SGf stage, the signals of cyp17-I 250 could be detected not only on theca cells, but throughout all the stromal cells around 251 the oocytes, especially in stalk-like tissues (a1-a3). For turbot, cyp17-I only expressed 252 on theca cells, not on the stromal cells around the oocytes at SGf stage (a4). 253 Cyp19a1a only expressed on granulosa cells, and the signals got stronger significantly 254 from SGe to SGl stages, and became weak at SGf stage (b1-b3). For turbot, the 255 signals of cyp19ala expressed on granulosa cells (b4). Fshr only expressed on 256 granulosa cells, and the signals got stronger significantly from SGe to SGl stage, but 257 the signals became very weak at SGf stage in black rockfish (c1-c3). For turbot, the 258 signals of $f$ shr expressed on granulosa cells (c4). Lama4 signals could not be detected 259 on theca cells until the oocytes developed to SGl stage, and significantly increased at 260 SGf stage on theca cells as well as the stromal cells around the oocytes in black 261 rockfish (d1-d3). For turbot, Lama4 had no signal at SGf stage (d4). HLA-E signals 262 could be detected on theca cells and stromal cells from SGe stage, and significantly 263 increased at SGf stage (e1-e3). TC, theca cells; GC, granulosa cells; PG, follicles with 264 primary growth; ZP, zona pellucida; SGe, early secondary growth; SGl, late secondary 265 growth; SGf, full secondary growth; F, follicle layers. Scale bars, $200 \mu \mathrm{m}$.

\subsection{Cyp17-I, cyp19, $f$ shr, lama4 and $H L A-E$ mRNA expression in gonad during}

\section{7 the pregnancy}

268 The expression of cyp17-I, cyp19ala, fshr, lama4 and HLA-E during pregnancy are 269 shown in figure 5. Cyp17-I signals presented strong on the follicular placenta at 270 blastula and gastrulae stage, and disappeared until prehatching stage (Fig. 5a1-a3). 271 HLA-E had the similar expression pattern with cyp17-I during gestation (Fig. 5e1-e3), 272 while $f$ shr and cyp19ala had no obvious signals during this period (Fig. 5b1-c3). 273 Lama4 expressed on the follicular placenta during the whole pregnancy period, the 274 signals were strong at blastula and gastrulae stage, and became weak at the 275 prehatching stage (Fig. 5d1-d3). For the isolated females, no obvious follicular 276 placenta structure was observed in the ovary, and only stromal cells, vascular 
structure and non-cellular structure surrounded the unfertilized eggs (Fig. 6a). And lama4, cyp17-I, cyp19ala and fshr did not show any signals, except for HLA-E(Fig. $6 b-f)$.

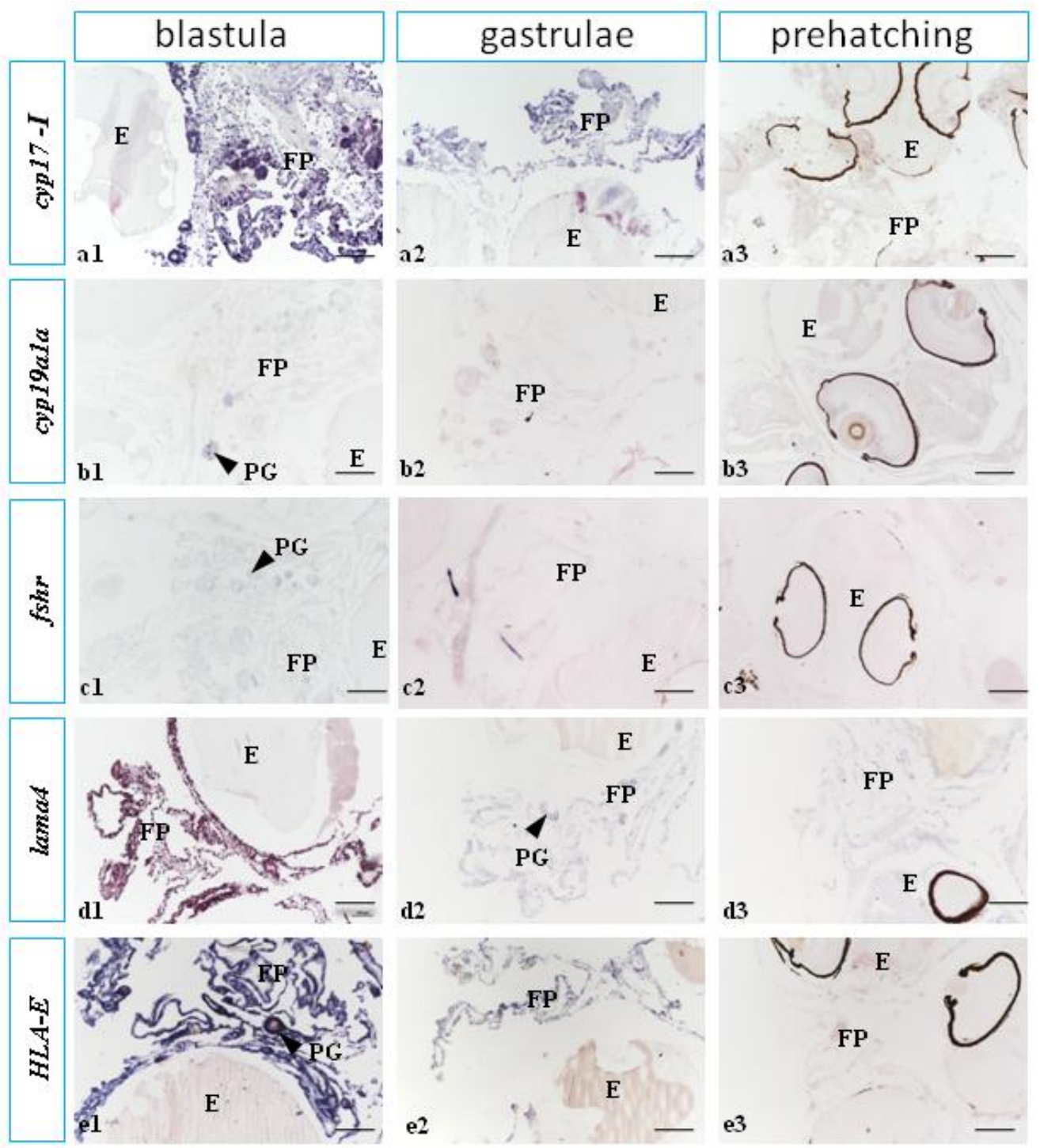

281 Figure 5. The expression of cyp17-I, cyp19ala, fshr, lama4 and HLA-E during 282 pregnancy. Cyp17-I signals presented strong on the follicular placenta at blastula and 283 gastrulae stage, and disappeared at prehatching stage (a1-a3). Cyp19ala had no 284 obvious signals during pregnancy (b1-b3). The expression of $f s h r$ during the gestation 285 of black rockfish. Fshr had no obvious signals during gestation (c1-c3). Lama4 expressed on the follicular placenta during the whole pregnancy period, the signals 287 were strong at blastula and gastrulae stage, and became weak in the prehatching stage 
288 (d1-d3). HLA-E signals presented strong on the follicular placenta at blastula and 289 gastrulae stage, and disappeared at prehatching stage (e1-e3). PG, follicles with 290 primary growth; FP, follicular placenta; E, embryos. Scale bars, $200 \mu \mathrm{m}$.

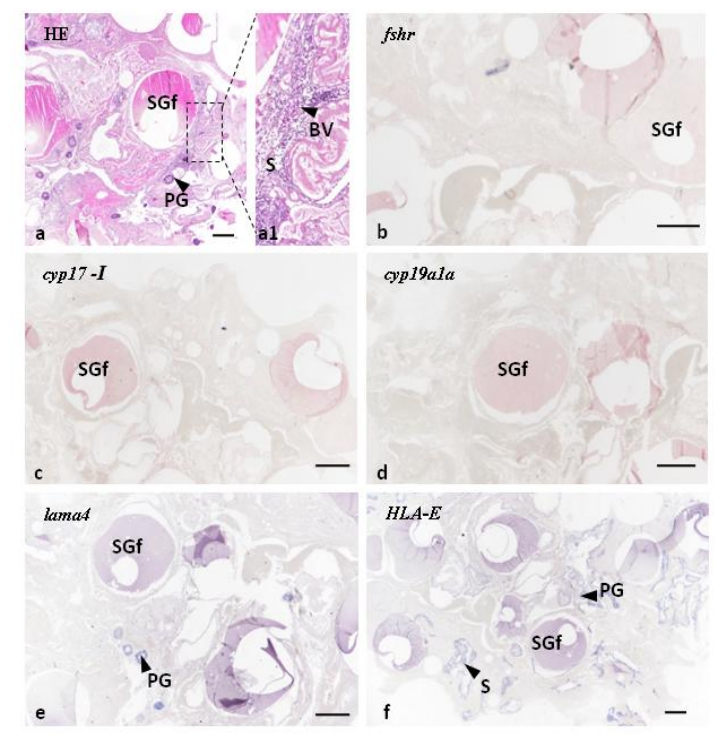

292 Figure 6. The morphogy and cyp17-I, cyp19ala, fshr, lama4 and HLA-E localization 293 in the isolated female black rockfish ovary. No obvious follicular placenta structure 294 was observed in the ovary, and only stromal cells, vascular structure and non-cellular 295 structure around the unfertilized eggs (a). Fshr, cyp17-I, and lama4 was not 296 expressed on connection tissues around the oocytes (b-e), except HLA-E (f). PG, 297 follicles with primary growth; SGf, full secondary growth; S, stromal cells; BV, blood 298 vessel. Scale bars, $200 \mu \mathrm{m}$.

\section{3. Discussion}

300 In black rockfish, we found a new type of folliculogenesis and placentation which is 301 different from the other viviparous teleost. Vitellogenesis of black rockfish is similar 302 to the turbot and other oviparous fish in general [37] (Fig. 7a, b). However, at SGe 303 stage, the germinal epithelium gradually surrounded the SGe oocytes and formed a lot 304 of individually developing follicles hanging on the ovigerous lamella with 305 vascularized stalk-like structures attaching to the stroma, which guaranteed each 306 follicle had opportunity contacting the spermatozoa as well as absorbing nutrition 
307 from ovary (Fig. 7b). After fertilization, we did not find the 2-cell structure outside 308 the embryos by histology, suggesting follicular layers ruptured before fertilization, 309 which was in line with the opinion of Bretschneider and Dewit [41]. After that, the 310 stored spermatozoa fertilized the eggs, and no distinct boundary between the 311 granulosa layer and theca layer were observed. The theca cells (with or without 312 granulosa cells) proliferated rapidly and invaded into the surrounding connective 313 tissue, becoming highly hypertrophied, extensively folded and highly vascularized, 314 and quickly formed a microvillous placenta at blastula stage. The structure strongly resembles other teleost placenta structures and the portion of mammalian 316 chorioallantoic placenta [8, 13, 26] (Fig. 7c).

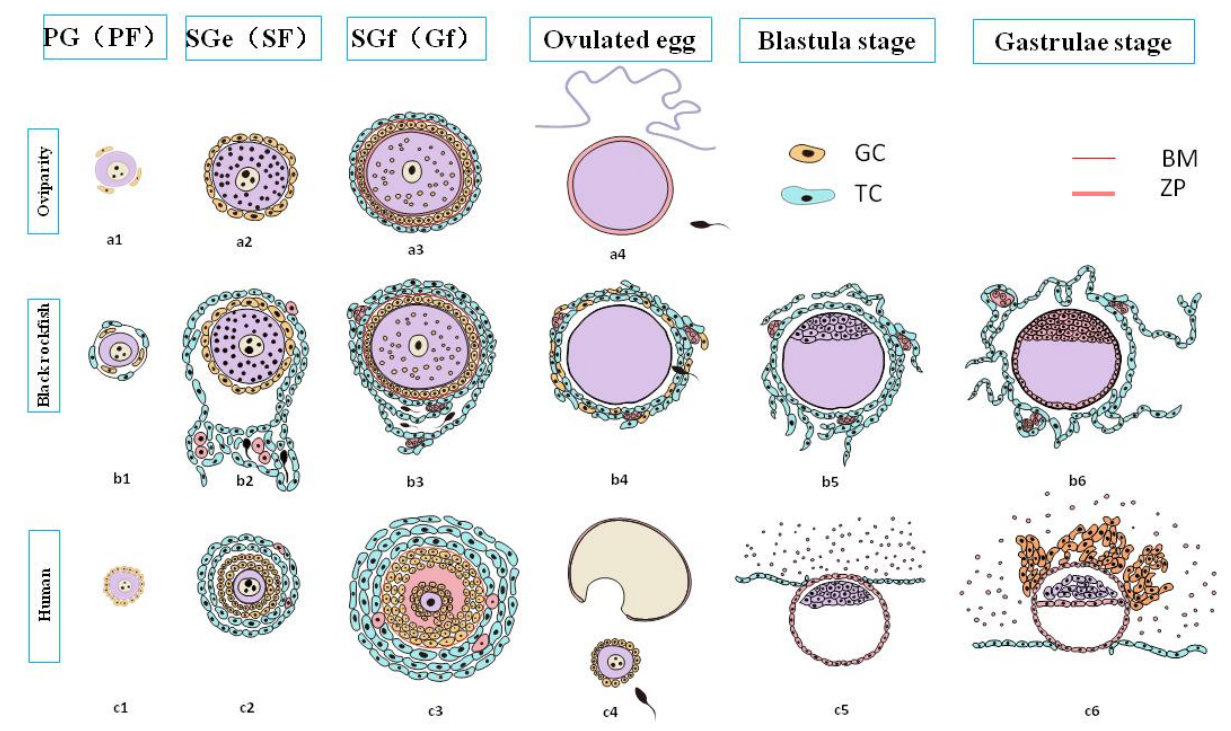

318 Figure 7. Cartoon illustrating the morphological difference during oogenesis and 319 placentation among turbot (oviparity), black rockfish and human. Oogenesis and 320 ovulation in turbot(oviparity) (a). After the follicles mature, the eggs are ovulated and 321 fertilized in the water (a4). Oogenesis and placentation in black rockfish (b). After the 322 follicles mature, the follicle layers rupture while the spermatozoa enter the micropyle 323 (b4), then theca cells rapidly proliferate, migrate and invade outward forming the 324 placenta (b5, b6). Oogenesis and placentation in human (c). After the follicles mature, 325 the eggs are ovulated from the ovary to the fallopian tubes (c4), the sperm and egg 326 unite to form a zygote (c5). Then the zygote travels down the fallopian tube and 
reaches the uterus. The morula becomes a blastocyst and implant into the uterine (c5, c6). PG, follicles with primary growth; SGe, early secondary growth; SGf, full secondary growth; PF, primary follicle; SF, secondary follicle; GF, graafian follicle; TC, theca cells; GC, granulosa cells; BM, basement membrane; ZP, zona pellucida. Intriguingly, we also found some conserved genes derived from the mammals placentation expressed strongly during the early gestation in black rockfish. Plgf, a member of the vascular endothelial growth factor family [42], exclusively expressed in the early gestation in black rockfish. It can regulate vasculogenesis and angiogenesis of the placenta, and cause endothelial cell proliferation, migration, and tube formation $[43,44,45]$. Plac8, first recognized as a placenta-specific transcribed gene in mouse [46], also strongly expressed from stage $\mathrm{V}$ to early gestation period in black rockfish as well as in the follicular placenta of P. retropinna [25]. Plac8 has been found promoting trophoblast invasion and migration [47, 48, 49]. In addition, tpbg is prominently expressed in cleavage and blastula stage in black rockfish. Tpbg is abundantly expressed at the apical microvillus surface of the syncytiotrophoblast throughout gestation, but rarely expressed in other tissues [50]. Besides that, TPBG is found to be released both from placental explants and perfused placenta, and sensitizes the maternal immune system [51]. All of the above results indicated black rockfish shared the homology with genes of placentation in pregnant mammals, which further confirmed the follicular placenta structure existing during its gestation period. Another interesting finding is that the ISH results from cyp17-I showed strong expression signals throughout the microvillous structure surrounding the embryos. Even before fertilization, the signals already exhibited obvious expansion especially in the stalk-like region. However, the $f$ shr and cyp19ala signals became weak at SGf stage and disappeared after fertilization, which also indicated the 2-cell structure breakdown, and granulosa cells lost the $\mathrm{E}_{2}$ synthesis function. Accordingly, the level of 11-KT progressively rose, peaked at blastula stage and remained a relative high level during the whole gestation period, while the $\mathrm{E}_{2}$ drastically decreased from stage IV and reached the bottom at blastula stage, then went back to a relatively high level. The high expression of cyp19alb in gestation period might partially explained the high $\mathrm{E}_{2}$ level during the mid to late gestation period [52]. Similarly, progesterone also 
358 kept a high level from blastula stage, suggesting its important role in supporting 359 pregnancy.

360 The changes of the three steroid hormone of black rockfish are similar to the 361 previous studies [30, 53], but we found the $\mathrm{E}_{2}$ rapidly declined to the bottom at 362 blastula stage, while the 11-KT peaked at the same time. The asynchronous secretion 363 of estrogen and androgen is different from the oviparous teleost, in which the $E_{2}$ and 364 11-KT synchronously change with the oocyte development [40]. Similar phenomenon 365 has been reported in the prostate cancer [54], in which CYP17A1 highly expressed 366 and mediated intracellular androgens synthesis. Risk of aggressive prostate cancer 367 was strongly inversely associated with estradiol: testosterone ratio [54], and 368 CYP17A1 is widely used as a target for the hormonal treatment of prostate cancer 369 [55]. The overexpression of cyp17-I at stage $\mathrm{V}$ led the unbalance between the 11-KT 370 and $\mathrm{E}_{2}$, which might be the driven factor for the theca cells proliferation and invasion 371 and form the microvillous placenta in black rockfish.

372 The site of gestation must be compartmentalized from the rest of the maternal 373 tissues to maintain the appropriate environment for embryonic. HLA-G is important 374 for the modulation of the maternal immune system during pregnancy, for it facilitates 375 trophoblast invasion and fusion with maternal uterine arteries through inhibiting NK 376 and T cell-mediated cell lysis [56, 57, 58, 59]. In this study, we identified HLA-E 377 from black rockfish, which had the same conserved domains as the human. HLA-E 378 and HLA-G all belong to the human MHC I genes [60, 61], and HLA-G was known 379 as the specific molecular typical marker of extravillous trophoblasts (EVT) $[62,63]$. 380 HLA-E also plays a role in inhibiting natural killer cells by interacting with the 381 CD94/NKG2A inhibitory receptor or activating CD94/NKG2C receptor [64]. The 382 results from both $I S H$ and transcriptom showed that HLA-E was significantly 383 expressed on the follicular placenta especially at SGf and blastula stage, which 384 indicated $H L A-E$ might play a similar role to $H L A-G$, faciliating the microvillous 385 structure invasion during the early gestation stage. At the same time, we found the 386 lama4 also had a similar expression pattern to HLA-E. Lama4 belongs to the laminin 387 family, which is the basement membrane component that promotes cell adhesion and 
angiogenesis [65]. LAMA4 was specifically localized in human first-trimester placental villi to syncytiotrophoblast cells and in the decidua to EVT cells, and promoted trophoblast invasion, migration and angiogenesis [66]. We also detected the strong expression of lama4 on the follicular placenta, suggesting the Lama4 is one of crucial factors in cell invasion and angiogenesis in black rockfish. In black rockfish, both HLA-E and lama4 were providing a microenvironment for placental cells proliferation, migration, invasion and signaling as reported in mammals [67], which to some extent provides evidence for convergent evolution at molecular level on placentation in vertebrates.

\section{Conclusion}

we firstly demonstrated a new type of follicular placenta formed in Scorpaenidae, and unveiled the placentation was derived from the cyp17-I drastically strong expression leading to the unbalance between the 11-KT and $\mathrm{E}_{2}$. In addition, we found some highly conserved genes expressed in mammalian placenta were also significantly expressed in the black rockfish follicular placenta structure, suggesting the high convergence both in the fish and mammalian placenta evolution. This finding provided a new type of placentation pattern for viviparous teleost between the intrafollicular gestation and intraluminal gestation.

\section{Materials and methods}

\subsection{Sample colletion}

Females black rockfish were collected from September to May from Nanshan market, Qingdao, China. In addition, we isolated some females in the Shenghang Sci-tech Co, Ltd. (Weihai, Shangdong Province, China) before copulation, and collected gonad samples when other females developed to the middle of pregnancy. The turbot (Scophthalmus maximus) samples were obtained from March to July from Shenghang Sci-tech Co, Ltd. (Weihai, Shangdong Province, China).

Before collecting ovaries, all fish were anesthetized in tricaine methanesulfonate (MS-222, Sigma, St. Louis, MO). Half of each ovary was stored in liquid nitrogen for molecular experiments and transcriptome analysis, one quarter was fixed overnight in Bouin's solution and preserved in 70\% ethanol for histology observation. And the other quarter was fixed overnight in $4 \%$ paraformaldehyde (PFA) and preserved in $70 \%$ 
ethanol for ISH. Blood samples were collected from the caudal vein, settling in $4^{\circ} \mathrm{C}$ overnight and centrifuging at $16,000 \mathrm{~g}$ for 10 minutes, and then stored at $-80^{\circ} \mathrm{C}$ for hormones determination.

\subsection{Total RNA extraction and cDNA synthesis}

Total RNA was extracted from black rockfish ovaries using SPARK easy tissue/cell RNArapid extraction kit (SparkJade, China) following the manufacturer's instructions. The RNA samples were determined by UV spectroscopy at 260 and $280 \mathrm{~nm}$ to measure concentration. The cDNA was synthesized by the PrimeScript ${ }^{\mathrm{TM}} \mathrm{RT}$ reagent Kit with gDNA Eraser (Takara, Japan) and stored at $-20^{\circ} \mathrm{C}$.

\subsection{Histology}

The histology followed the methods described by Yang et al. [68]in our laboratory(. The fixed samples were dehydrated and embedded and then sliced, with a thickness of 5um (Leica 2235). After hematoxylin-eosin (H\&E) staining, the morphological structures were observed under the microscope (NikonENi, Japan) at different stages.

\subsection{In situ hybridization and the fluorescence in situ hybridization}

The full length of the HLA-E sequence was obtained by our existing transcriptome data, the primers were shown in table 1 . The synthesized cDNA was inserted into a pGEM-T Easy vector (Promega, Madison, WI) and the full length was verified by sequencing.

The full length of cyp17-I, fshr and cyp19ala of black rockfish were carried out using the National Center for Biotechnology Information website(GenBank: ADV59774.2, AEJ33654, ACN39247), and the sequence of lama4 was obtained by our existing transcriptome data.

The full length of cyp17-I, fshr, cyp19ala and lama4 of turbot were carried out using the National Center for Biotechnology Information website (GenBank: XM_035606144.1:142-1371， XM_035611916.1，～XM_035627469.1，

XM_035618004.1 ). Referring to a previous article [69] , for each gene, primers F and $\mathrm{R}$ were used to amplify the cDNA fragment, and the product was used for the second round PCR using the primers F and R-T7 for generating antisense probe and primers $\mathrm{R}$ and F-T7 for generating sense probe used in ISH assays with the DIG RNA Labeling Kit (Roche, Mannheim, Germany), the primers were shown in table 1. After 
450 ISH, the samples were then stained with neutral eosin.

451 Table1. Primers and probes used for cloning and ISH

\begin{tabular}{lll}
\hline Primer & Sequence(5'-3') & Purpose \\
\hline HLA-E-ORF-F & ATGAATTTGATCGCAGTCTT & ORF amplification \\
HLA-E-ORF-R & TCACCTCGCCAGTGTTGCTA & ORF amplification \\
HLA-E-ISH-F & AAACGCATGAGACAGAGCGA & ISH probe \\
HLA-E-ISH-R & CCAGGCACACCAAAATGACG & ISH probe \\
HLA-E-ISH-T7R & TAATACGACTCACTATAGGGCCAGGCACACCAAAATGACG & ISH probe \\
cyp17-I-ISH-F & ACCAACGTCATCTGTTCGCT & ISH probe \\
cyp17-I-ISH-R & GCTCCTCCTGGATACGCTTC & ISH probe \\
cyp17-I-ISH-T7R & TAATACGACTCACTATAGGGGCTCCTCCTGGATACGCTTC & ISH probe \\
sshr-ISH-F & CGTTGAAGGGCATAGGGGAT & ISH probe \\
fshr-ISH-R & AGGCATTGGCGGGGACTATC & ISH probe \\
fshr-ISH-RT7 & TAATACGACTCACTATAGGGAGGCATTGGCGGGGACTATC & ISH probe \\
cyp19ala-ISH-F & TTCACCATGCGTAAAGCCCT & ISH probe \\
cyp19ala-ISH-R & GGCTGCTGAGAGAGGTTGTT & ISH probe \\
cyp19ala-ISH-T7R & TAATACGACTCACTATAGGGGGCTGCTGAGAGAGGTTGTT & ISH probe \\
lama4-ISH-F & CCGAGGACTTCCAGCGATAC & ISH probe \\
lama4-ISH-R & GCGCCGTCGTTGTATTTCTC & ISH probe \\
lama4-ISH-T7R & TAATACGACTCACTATAGGGGCGCCGTCGTTGTATTTCTC & ISH probe \\
\hline
\end{tabular}

453 Two-color in the fluorescence in situ hybridization experiment was performed 454 following the instructions of DIG RNA Labeling Kit (Roche, Mannheim, Germany). 455 When synthesizing probe, cyp17-I and cyp19ala were labelled with digoxin, and 456 fluorescein, and detected by anti-dig and anti-fluorescein-POD antibodies, 457 respectively.

\section{$458 \quad 5.5$ Transcriptome analysis}

459 Transcriptome analysis referred to a previous article (Wang et al,. 2018)[70]. 460 Twenty-four cDNA libraries (FII, FIII, FIV, FV, Cleavage, Blastula, Gastrulae, 461 Prehatching) were constructed using total RNA from female ovaries at different 462 development stage. The clean reads were assembled into non-redundant transcripts, 463 which are then clustered into Unigenes. There were three biological repetitions for 464 each stage.

\section{$465 \quad 5.6$ Hormones determination}

466 The $\mathrm{E}_{2}, 11-\mathrm{KT}$, and P levels were tested by Iodine [125I] Radioimmunoassay (RIA) 467 kits (Beijing North, China) respectively with the manufacturer's instructions. The 
468 binding rate is highly specific with low cross-reactivity to other steroids, which was 469 less than $0.1 \%$ to most circulating steroids.

\section{$470 \quad 5.7$ Statistical analysis}

471 The amino acid sequences of HLA-E of black rockfish was deduced using 472 DNAMAN 8 software. The conserved domains of HLA-E genes in humans and black 473 rockfish were predicted online through SMART(http://smart.embl-heidelberg.de/). 474 Phylogenetic analysis was conducted with Mega7 software using the neighbor-joining 475 method. The heat map was drawn with $\mathrm{R}$ software (3.5.3) based on the existing 476 transcriptome data. FPKM (expected number of Fragments Per Kilobase of transcript 477 sequence per Millions base pairs sequenced) was used to calculate the gene 478 expression levels.

\section{6. List of abbreviations}

\begin{tabular}{cc}
\hline abbreviations & The full name \\
\hline L & lumen \\
OL & ovigerous lamella \\
IT & intersticial tissue \\
PG & follicles with primary growth \\
GE & germinal epithelium \\
TC & theca cells \\
GC & granulosa cells \\
BM & basement membrane \\
YG & yolk globule \\
BV & blood vessel \\
ZP & zona pellucida \\
S & stroma \\
SGf & full secondary growth \\
Sge & early secondary growth \\
F & follicle layers \\
FP & follicular placenta \\
E & embryo \\
SGl & late secondary growth \\
PE & primary follicle \\
SF & secondary follicle \\
GF & graafian follicle. \\
\hline Tfes & and consent to participa
\end{tabular}

\section{Ethics approval and consent to participate}

481 All experiments were performed in accordance with the relevant national and 482 international guidelines and approved by the Institutional Animal Care and Use 483 Committee, Institute of Oceanology, Chinese Academy of Sciences. 
Consent for publication

\section{Availability of data and materials}

\section{Competing interests}

487 The authors declare that no competing interests exist.

$488 \quad$ Funding

\begin{tabular}{lll}
\hline \multicolumn{1}{c}{ Funder } & Grant reference number & \multicolumn{1}{c}{ Author } \\
\hline National Key Research and Development Program & 2018YFD0901205 & Qinghua Liu \\
National Key Research and Development Program & 2018YFD0901204 & Jun Li \\
& CARS-47 & Jun Li \\
China Agriculture Research System & 2019JZZY020710 & Jun Li \\
Major Science and Technology Innovation Projects & & \\
\hline
\end{tabular}

The funders had no role in study design, data collection and interpretation, or the

490 decision to submit the work for publication.

491 Author contributions

492 Xiaojie Xu, Conceptualization, Data curation, Formal analysis, Investigation, 493 Methodology, Writing - original draft; Qinghua Liu, Conceptualization, Data curation, 494 Formal analysis, Investigation, Methodology, Writing - review and editing, Funding 495 acquisition, Supervision; Xueying Wang, Conceptualization, Formal analysis, 496 Methodology; Xin Qi, Hormones level tests; Li Zhou, Methodology; Haoming Liu, 497 fish culture; Jun Li, Supervision, Funding acquisition, Validation, Project 498 administration

499 Acknowledgement

500 This research was supported by National Key Research and Development Program 501 (NO. 2018YFD0901205 2018, YFD0901204) and China Agriculture Research 502 System (NO. CARS-47), and Major Science and Technology Innovation Projects $5032019 J Z Z Y 020710$.

\section{Authors' information}

505 1CAS and Shandong Province Key Laboratory of Experimental Marine Biology, 506 Center for Ocean Mega-Science, Institute of Oceanology, Chinese Academy of 507 Sciences, Qingdao, China

508 2Laboratory for Marine Biology and Biotechnology, Qingdao National Laboratory for

509 Marine Science and Technology, Qingdao, China.

510 3University of Chinese Academy of Sciences, Beijing 100049, China.

511 4Key Laboratory of Mariculture (Ocean University of China), Ministry of Education, 512 Ocean University of China, Qingdao 266003, PR China. 
513 5Weihai Shenghang Aquatic Science and Technology Co., LTD. Weihai,China.

514 6Fisheries Research Institute of Huancui District, Weihai China.

515

516 aThese authors contributed equally to this work.

517 *For correspondence: Qinghua Liu, qinghualiu@qdio.ac.cn; Jun Li, junli@ qdio.ac.cn

518 Competing interest: See page ;

519 Funding: See page 21

\section{Reference}

521 [1] Kalinka AT. 2015. How did viviparity originate and evolve? of conflict, co-option,

522 and cryptic choice. BioEssays 37,721-731. DOI : 10.1002/bies.201400200

523 [2] Wourms JP., and Callard IP. 1992. A retrospect to the symposium on evolution of viviparity in vertebrates. American Zoologist 32(2), 251-255. DOI:10.1093/ICB/32.2.251

526 [3] Wourms JP. 1993. Maximization of evolutionary trends for placental viviparity in 527 the spadenose shark, Scoliodon laticaudus. The reproduction and development of 528 sharks, skates, rays and ratfishes. Springer Netherlands. 32, 251-255. DOI:10.1007/BF00842922

530 [4] Blackburn and Daniel G. 2015. Evolution of vertebrate viviparity and 531 specializations for fetal nutrition: A quantitative and qualitative analysis. Journal 532 of Morphology 276(8), 961-990. DOI : 10.1002/jmor.20272

533 [5] Kunz YW. 2004. Developmental Biology of Teleost Fishes. Springer Netherlands. $534 \quad$ ISBN : 978-1-4020-2996-7.

535 [6] Blackburn DG. 2005. Evolutionary origins of viviparity in fishes. Viviparity in 536 Fishes. (H.J. Grier and M.C.Uribe, editor) pages 287-301,New Life Publications Homestead, Florida.

538 [7] Carcupino M , Baldacci A , Mazzini M, Franzoi P 2002. Functional significance 539 of the male brood pouch in the reproductive strategies of pipefishes and 540 seahorses: a morphological and ultrastructural comparative study on three 541 anatomically different pouches. Journal of Fish Biology 61,1465-1480. DOI :10.1111/j.1095-8649.2002.tb02490.x 
543 [8] Kwan L, Fris M, Rodd FH., Rowe L, Tuhela L, Panhuis TM. 2015. An 544 examination of the variation in maternal placentae across the genus Poeciliopsis 545 (Poeciliidae). Journal of Morphology 276(6):707 - 720. DOI : $546 \quad 10.1002 /$ jmor.20381

547 [9] Roberts RM, Green JA, Schulz LC. 2016. The evolution of the placenta. $548 \quad$ Reproduction 152, R179-R189. DOI : 10.1530/REP-16-0325

549 [10] Turner CL. 1940. Pseudoamnion, pseudochorion, and follicular pseudoplacenta 550 in poeciliid fishes. Journal of Morphology 67(1), 59-89. DOI: 551 10.1002/jmor.1050670103

553

[11] Knight FM, Lombardi J, Wourms JP, Burns JR. 1985. Follicular placenta and embryonic growth of the viviparous foureyed fish (Anableps). Journal of Morphology 185,131-142. DOI : 10.1002/jmor.1051850110

[12] Buddle AL, Van Dyke JU, Thompson MB, Simpfendorfer CA, Whittington CM. 556 2018. Evolution of placentotrophy: using viviparous sharks as a model to understand vertebrate placental evolution. Marine and Freshwater Research, 70. 908-924. DOI: 10.1071/MF18076

[13] Laksanawimol P, Damrongphol P, Kruatrachue M. 2006. Alteration of the brood pouch morphology during gestation of male seahorses, Hippocampus kuda. Marine and Freshwater Research 57(5), 497. DOI : 10.1071/MF05112.

[14] Stolting, KN, Wilson AB. 2007. Male pregnancy in seahorses and pipefish: beyond the mammalian model. BioEssays 29(9), 884-896. DOI : 10.1002/bies.20626

[15] Larsson DGJ , Mayer I, Hyllner SJ , Forlin L. 2002. Seasonal Variations of

[16] Reznick DN, Mateos M, Springer MS. 2002. Independent origins and rapid 570 evolution of the placenta in the fish genus poeciliopsis. Science 298(5595), $571 \quad$ 1018-1020. DOI : 10.1126/science.1076018. 
572 [17] Wourms, JP, Grove BD, Lombardi J. 1988. The maternal-embryonic

573

574

575

576

577

578

579

580

581

582

583

584

585

586

587

588

589

590

591

592

593

594

595

596

597

598

599

600

relationship in viviparous fishes. Fish Physiology, 11, 1-134. DOI: 10.1016/S1546-5098(08)60213-7

[18] Schindler JF, Hamlett WC. 1993. Maternalembryonic relations in viviparous teleosts. Journal of Experimental Zoology. 266(5), 378-393. DOI: 10.1002/jez.1402660506

[19] Turner, C. L. 1947. Viviparity in teleost fishes. The Scientific monthly, 65(6), 508-518. DOI : $10.1086 / 265911$

[20] Wake WH. 1985. Oviduct structure and function innon-mammalian vertebrates. Fortschritte Der Zoologie 30:427-435.

[21] Campuzano-Caballero JC, Uribe MC. 2014. Structure of the female gonoduct of the viviparous teleost poecilia reticulata (poeciliidae) during nongestation and gestation stages. Journal of Morphology, 275(3), 247-257. DOI : 10.1002/jmor.20200

[22] Van Dyke JU, Brandley MC, Thompson MB. 2014. The evolution of viviparity: molecular and genomic data from squamate reptiles advance understanding of live birth in amniotes. Reproduction 147 R15-R26. (doi:10.1530/rep-13-0309)

[23] Burton GJ, Jauniaux E. 2015. What is the placenta?. American Journal of Obstetrics \& Gynecology 213(4), 6-8. DOI : 10.1016/j.ajog.2015.07.050

[24] Wourms JP, Whitt GS. 1981. Future directions of research on the developmental biology of fishes. The American Zoologist 21, 597-604. DOI : 10.2307/3882652

[25] Guernsey MW, Henri VK, Reznick DN, Pollux BJA, Baker JC. 2020. Molecular signatures of placentation and secretion uncovered in poeciliopsis maternal follicles. Molecular Biology and Evolution 37(9), 2679-2690 DOI : 10.1093/molbev/msaa121

[26] Grove BD, Wourms JP. 1994. Follicular placenta of the viviparous fish, Heterandria formosa: II. Ultrastructure and development of the follicular epithelium. Journal of Morphology 220(2):167 - 184. DOI : 10.1002/jmor.1052200206 
601 [27] Lombardi J, Wourms JP. 1985. The trophotaenial placenta of a viviparous goodeid fish. iii: protein uptake by trophotaeniae, the embryonic component (p165-179). Journal of Experimental Zoology 236, 165-179. DOI :

604

605

606

607

608

609

610

611

612

613

614

615

616

617

618

619

620

621

622

623

624

625

626

627

628

629

10.1002/jez.1402360207

[28] Moser HG. 1967b. Seasonal histological changes in the gonads of Sebastodes paucispinis Ayers, an ovoviviparous teleost (family scorpaenidae). Journal of Morphology 123, 333-336. DOI : 10.1002/jmor.1051230403

[29] Shi D, Wen HS, He F, Li JF, Yang YP, Chen CF, Zhang JR, Chen XY, Jin GX, Bao S. 2011. The physiology functions of estrogen receptor $\alpha(E r \alpha)$ in reproduction cycle of ovoviviparous black rockfish, Sebastes schlegeli hilgendorf. Steroids, 76(14), 1597-1608. DOI : 10.1016/j.steroids.2011.09.014

[30] Mori H, Nakagawa M, Soyano K, Koya Y. 2003. Annual reproductive cycle of black rockfish Sebastes schlegeli in captivity. Fisheries Science 69(5), 910-923. DOI : 10.1046/j.1444-2906.2003.00707.x

[31] Grier HJ, Uribe MC, Parenti LR, De la Rosa-Cruz G. 2005. Fecundity, the germinal epithelium, and folliculogenesis in viviparous fishes. In: Uribe MC, Grier HJ, editors. Viviparous Fishes. Homestead, FL: New Life Publications. pp $191-126$.

[32] Nakagawa M. 1998. Broodstock management of black rockfish. Annual Report of Japan Sea-Farming Association in 1996 32-33. (In Japanese)

[33] Nakagawa M. 1999. Broodstock management of black rockfish. Annual Report of Japan Sea-Farming Association in 1997 34-36. (In Japanese)

[34] Nakagawa M. 2000. Broodstock management of black rockfish. Annual Report of Japan Sea-Farming Association in 1998 40-42. (In Japanese)

[35] Nakagawa M. 2001. Broodstock management of black rockfish. Annual Report of Japan Sea-Farming Association in 1999 42-44. (In Japanese)

[36] Nakagawa M, Ichikawa T, Maekawa H. 2002. Broodstock management of black rockfish. Annual Report of Japan Sea-Farming Association in 2000 38-39. (In Japanese). 
[37] Lubzens E, Young G, Bobe J, Joan Cerdà. 2010. Oogenesis in teleosts: how fish eggs are formed. General \& Comparative Endocrinology, 165(3), 367-389. DOI : 10.1016/j.ygcen.2009.05.022

[38] Sreenivasulu G, Senthilkumaran B. 2009. A role for cytochrome p450 634 635 17alpha-hydroxylase/c17-20 lyase during shift in steroidogenesis occurring in

[39] Miller WL, Auchus RJ, Geller DH. 1997 The regulation of 17,20 lyase activity. Steroids 62:133-142. DOI : 10.1016/S0039-128X(96)00172-9

[40] Kagawa H. 2013. Oogenesis in teleost fish. Aqua-BioScience Monographs, 6(4), 99-127. DOI : 10.5047/absm.2013.00604.0099

[41] Bretschneider LH, DeWitt JJD. 1947. Sexual endocrinology of non-mammalian 642 vertebrates. Elselvier, Amsterdam. $146 \mathrm{pp}$

[42] Arroyo JA, Winn VD. 2008. Vasculogenesis and angiogenesis in the iugr placenta. Seminars in Perinatology, 32(3), 172-177. DOI : 10.1053/j.semperi.2008.02.006

[42] Otrock ZK, Makarem JA, Shamseddine AI. 2007. Vascular endothelial growth factor family of ligands and receptors: review. Blood Cells Mol Dis, 38(3), 258-268. DOI : 10.1016/j.bcmd.2006.12.003

[44] Tammela T, Enholm B, Alitalo K, Paavonen K. 2005. The biology of vascular endothelial growth factors. Cardiovascular research 65, 550-563. DOI : 10.1016/j.cardiores.2004.12.002

[44] Wallner W, Sengenberger R, Strick R, Strissel P, Meurer B, Beckmann M, et al. 2007. Angiogenic growth factors in maternal and fetal serum in pregnancies complicated by intrauterine growth restriction. Clinical Science 112(1), 51-7. DOI : 10.1042/CS20060161

[46] Galaviz-Hernandez C, Stagg C, Ridder GD, Tanaka TS, Ko MSH, Schlessinger D, et al. 2003. Plac8 and plac9, novel placental-enriched genes identified through 
microarray analysis. Gene, 309(2), 81-89. DOI : $10.1016 / \mathrm{S} 0378-1119(03) 00508-0$

660 [47] Mourtada-Maarabouni M, Watson D, Munir M, Farzaneh F, Williams GT. 2013. Apoptosis suppression by candidate oncogene PLAC8 is reversed in other cell types. Current Cancer Drug Targets 13, 80-91. DOI : $10.2174 / 156800913804486584$

[48] Rogulski K, Li Y, Rothermund K, Pu L, Watkins S, Yi F , et al. 2005. Onzin, a c-myc-repressed target, promotes survival and transformation by modulating the akt-mdm2-p53 pathway. Oncogene, 24(51), 7524-7541.

[49] Chang WL, Liu YW, Dang YL, Jiang XX, Xu H, Huang X, et al. 2018. Plac8, a new marker for human interstitial extravillous trophoblast cells, promotes their invasion and migration. Development 145(2): $\operatorname{dev} 148932 . \quad$ DOI : 10.1242/dev.148932.

[50] Hole N, Stern P. 1988. A $72 \mathrm{kd}$ trophoblast glycoprotein defined by a monoclonal antibody. British Journal of Cancer 57(3), 239. DOI : 10.1038/bjc.1988.53

[51] Alam SMK, Jasti S, Kshirsagar SK, Tannetta DS, Petroff MG. 2017. 675 Trophoblast glycoprotein (tpgb/5t4) in human placenta: expression, regulation, and presence in extracellular microvesicles and exosomes. Reproductive

[52] Kwon JY, Kim J. 2013. Differential expression of two distinct aromatase genes 683 Sciences, 25(2) 185-197. DOI : 10.1177/1933719117707053

[52] Black A, Pinsky PF, Grubb RL, Falk RT, Hsing AW, Chu LS, et al. 2014. Sex steroid hormone metabolism in relation to risk of aggressive prostate cancer . Cancer Epidemiology, Biomarkers \& Prevention 23(11), 2374-2382 DOI: expression analysis of the cytochrome p450c17s enzymes during the 
reproductive cycle in ovoviviparous korean rockfish (sebastes schlegeli). Gene, 512(2), 444-449. DOI : 10.1016/j.gene.2012.10.064

[55] David J, Einstein, Seiji, Arai, Steven, P, Balk. 2019. Targeting the androgen receptor and overcoming resistance in prostate cancer. Current opinion in oncology. 31(3): 175-182. DOI : 10.1097/CCO.0000000000000520

[56] Navarro F, Llano M, Teresa Bellón, Colonna M, Geraghty DE, Miguel LópezBotet. 1999. The ilt2(lir1) and cd94/nkg2a nk cell receptors respectively recognize hla-g1 and hla-e molecules co-expressed on target cells. European Journal of Immunology, 29(1), $277-283$ DOI : 10.1002/(SICI)1521-4141(199901)29:01<277::AID-IMMU277>3.0.CO;2-4

[57] Rajagopalan S and Long EO. 1999. A human histocompatibility leukocyte antigen (HLA)-G-specific receptor expressed on all natural killer cells. The Journal of experimental medicine 189,1093-1100. DOI :10.1084/jem.189.7.1093

[58] Riteau Béatrice, Catherine M, Iman KD, Silvia M, Marika P, Jean D, et al. (2001). HLA-G1 co-expression boosts the HLA class I-mediated NK lysis inhibition. International Immunology $\quad 13,193-201$. DOI : 10.1002/asi.20617

[59] Ishitani A, Sageshima N, Lee N, Dorofeeva N, Hatake K, Marquardt H, et al. 2003. References subscriptions permissions email alerts protein expression and peptide binding suggest unique and interacting functional roles for HLA-E, F, and $\mathrm{G}$ in maternal-placental immune recognition. Journal of Immunology, 171(3), 1376-1384. DOI : 10.4049/jimmunol.171.3.1376

[60]Geraghty DE, Koller BH, Orr HT. 1987. A human major histocompatibility complex class I gene that encodes a protein with a shortened cytoplasmic segment. Proceedings of the National Academy of Sciences of the United States of America 84(24), 9145-9149. DOI : 10.1073/pnas.84.24.9145

[61] Geraghty DE, Wei XH, Orr HT, Koller BH. 1990. Human leukocyte antigen F (HLA-F) An expressed HLA gene composed of a class I coding sequence linked 
to a novel transcribed repetitive element. Journal of Experimental Medicine 171(1), 1-18. DOI : 10.1084/jem.171.1.1

717 [62] Ellis S. 1990. HLA- G: at the interface. American Journal of Reproductive Immunology, 23(3), 84-86. DOI : 10.1016/0093-691X(90)90533-Y

[63] Kovats S , Main E K , Librach C , Stubblebine M , Fisher S J , DeMars R. 1990. A class I antigen, HLA-G, expressed in human trophoblasts. Science (New York,

[64] Braud VM, Allan DS, O' Callaghan CA, Söderström K, D' Andrea A, Ogg GS, Lazetic S, Young NT, Bell JI, Phillips JH, et al. 1998. HLA-E binds to natural killer cell receptors CD94/NKG2A, B and C.

C. Nature,391, 795-799. DOI : $10.1038 / 35869$

[65] Givant-Horwitz V, Davidson B, Reich R. 2004. Laminin-induced signaling in tumor cells: the role of the m-r 67,000 laminin receptor. Cancer Research, 64(10),

[66] Shan N, Zhang X, Xiao X, Zhang H, Qi H. 2015. Laminin a 4 (lama4) 3572-3579. DOI : 10.1158/0008-5472.CAN-03-3424

733

[68] Yang Y, Liu Q, Xiao Y, Xu S, Wang X, Yang J, Song Z, You F, Li J. 2018. 738 High temperature increases the gsdf expression in masculinization of genetically female japanese flounder (paralichthys olivaceus). General \& Comparative Endocrinology 274 (2019) 17-25. DOI : 10.1016/j.ygcen.2018.12.012 
741 [69] Wang S, Zhang J, Jiao W, Li J, Xun X, Sun Y, Guo X et al. 2020. Scallop 742 genome provides insights into evolution of bilaterian karyotype and development. 743 Nature Ecology \& Evolution, 1(5), 1-12. DOI: 10.1038/s41559-017-0120

744 [70] Wang X, Liu Q, Xu S, Xiao Y, Wang Y, Feng C, Xue R, Zhao H, Song Z, Li 745 J. 2018 Transcriptome Dynamics During Turbot Spermatogenesis Predicting the 746 Potential Key Genes Regulating Male Germ Cell Proliferation and Maturation. 747 Scientific Reports 8(1), 1-12. DOI: 10.1038/s41598-018-34149-5 


\section{Figures}

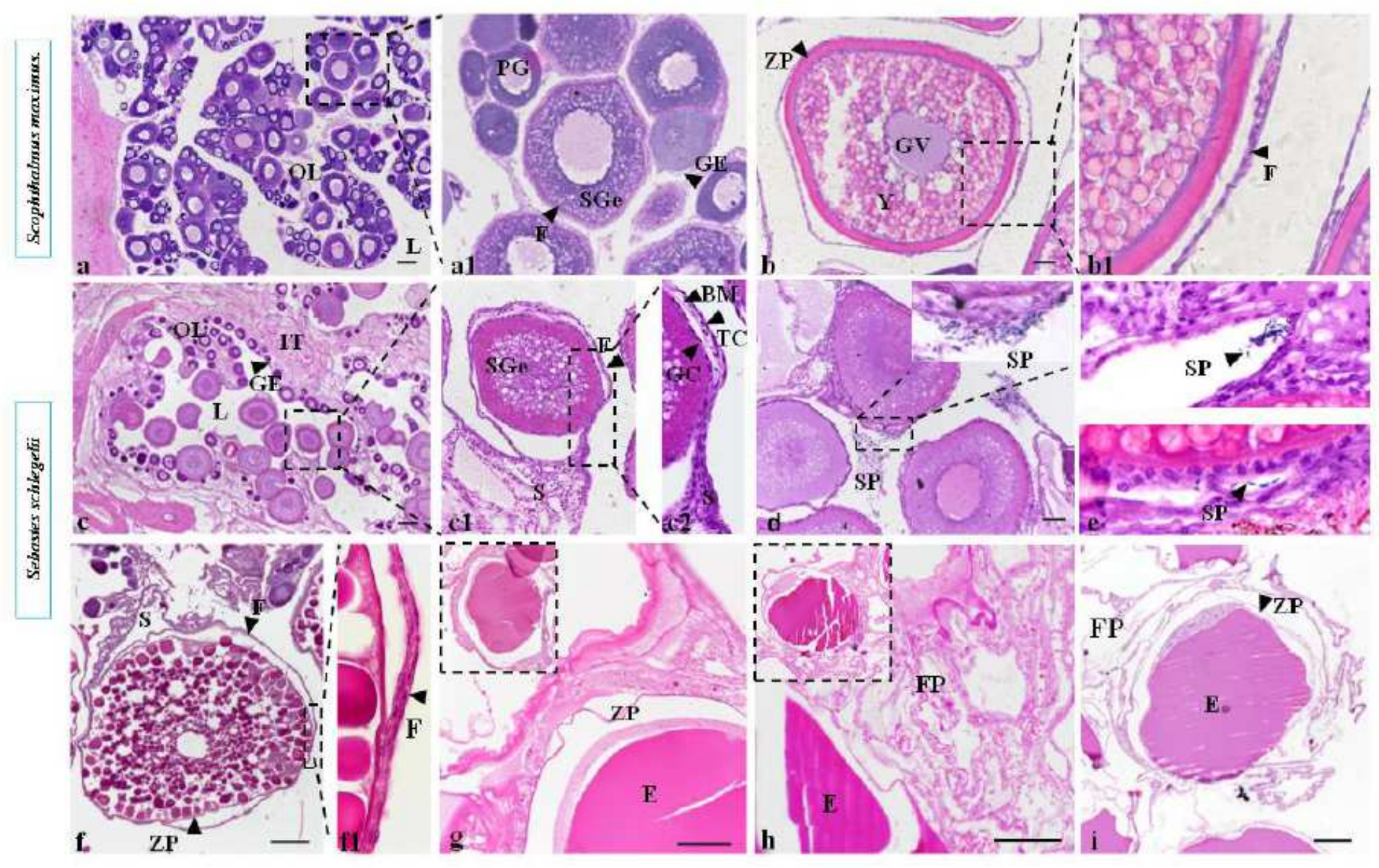

Figure 1

Oogenesis and embryonic development of black rockfish compared with turbot. Numerous primary growth oocytes and early secondary growth (SGe) oocytes surrounded by follicle cells in the stage III ovary of turbot (a, a1). Full secondary growth (SGf) oocytes surrounded by a thick zona pellucida (ZP) and thin follicle cells $(F)$ in the stage $V$ ovary of turbot $(b, b 1)$. Numerous primary growth oocytes and early secondary growth (SGe) oocytes surrounded by follicle cells in the stage III ovary of black rockfish (c, c1). Numerous spermatozoa of scatter in the ovarian lumen outside of the follicles in the stage III ovary of black rockfish (d, d1). Numerous spermatozoa hide in the crypt of the stromal cells or the folds outside of the follicles in the stage IV ovary of black rockfish (e). SGf oocytes are surround by a thin ZP and follicular layers in the stage $V$ ovary of black rockfish (f). At cleavage stage, the granulosa cells have detached from the oocyte and the follicular layers (granulosa layer, theca layer and basement membrane ) mixed with the surrounding epithelium and stroma cells and formed follicular placenta (g). Follicular placenta structure became highly hypertrophied, extensively folded at blastula stage (h). Follicular placenta became more loose at gastrulae stage (i). L, lumen; OL, ovigerous lamella; IT, intersticial tissue; PG, follicles with primary growth; GE, germinal epithelium; TC, theca cells; GC, granulosa cells; BM, basement membrane; YG, yolk globule; BV, blood vessel; ZP, zona pellucida; S, stroma; SGf, full secondary

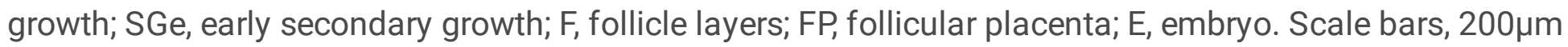


A

a

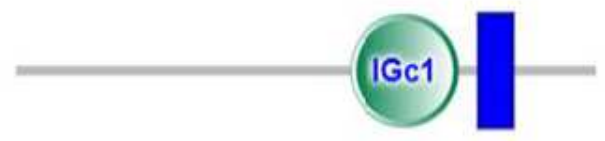

$\mathrm{b}$

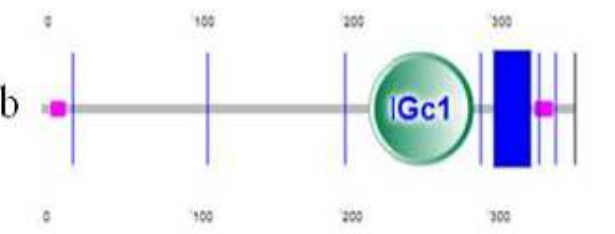

B

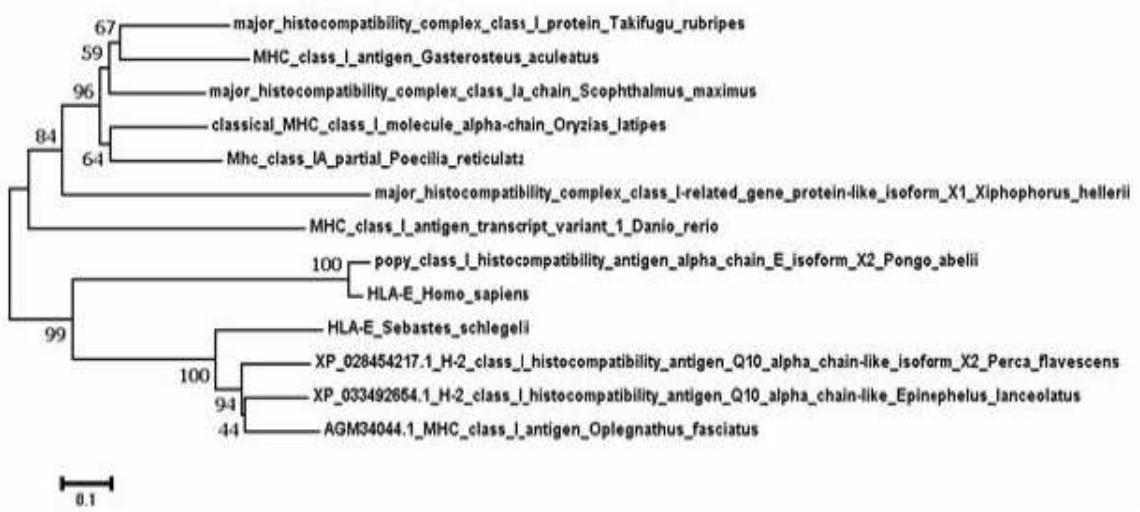

Figure 2

The conserved domains and phylogenetic tree of HLA-E in black rockfish A. The HLA-E of black rockfish has the same conserved domains as humans. Conserved domains of black rockfish (a). Conserved domains of human (b). B. The phylogenetic tree of the major histocompatibility complexclass I family (MHC- $\mathrm{\Xi}$ ) includes black rockfish and other vertebrates using predicted amino acid sequences. The GenBank accession numbers are as follows: Xiphophorus macufulls H-2 class I histocompatibility antigen, alpha chain-like (XP_023201134.1), Poecilia reticufull PREDICTED: H-2 class I histocompatibility antigen, Q10 alpha chain-like isoform X1 (XP_008420844.1), Homo sapiens HLA-E (ARB08449.1), Pongo abeliipopy class I histocompatibility antigen, alpha chain E isoform X2 (XP_024104292.1), Danio rerioMHC class I antigen transcript variant 1 (ALL98461.1), Gasterosteus 146 aculeatus MHC class I antigen (ABN14357.1), Scophthalmus maximusmajor histocompatibility complex class la chain (ABM92962.1), Takifugu rubripes major histocompatibility complex class I protein (AAC41236.1), Oryziaslatipes classical MHC class I molecule, alpha-chain (BAJ07297.2), Oplegnathus fasciatus MHC class I antigen (AGM34044.1), Perca flavescensH-2 class I histocompatibility antigen, Q10 alpha chainlike isoform X2 (XP_028454217.1), EpinepheluslanceolatusH-2 class I histocompatibility antigen, Q10 alpha chain-like (XP_033492654.1). 
A

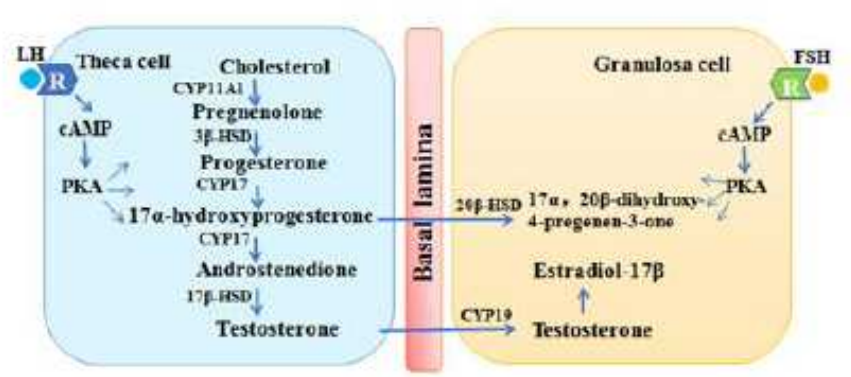

D

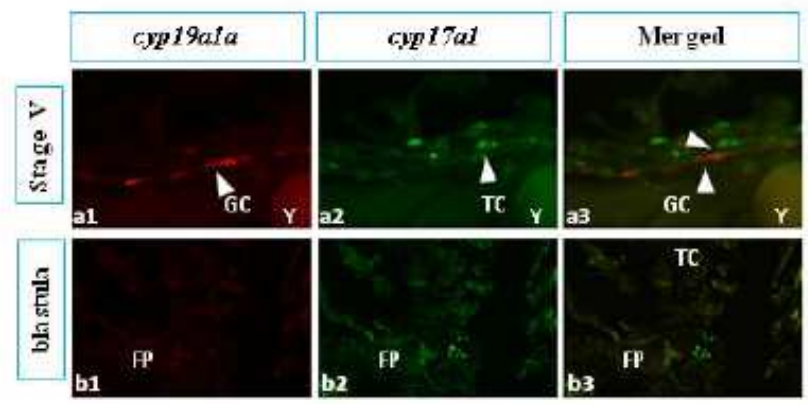

B

$\mathrm{C}$
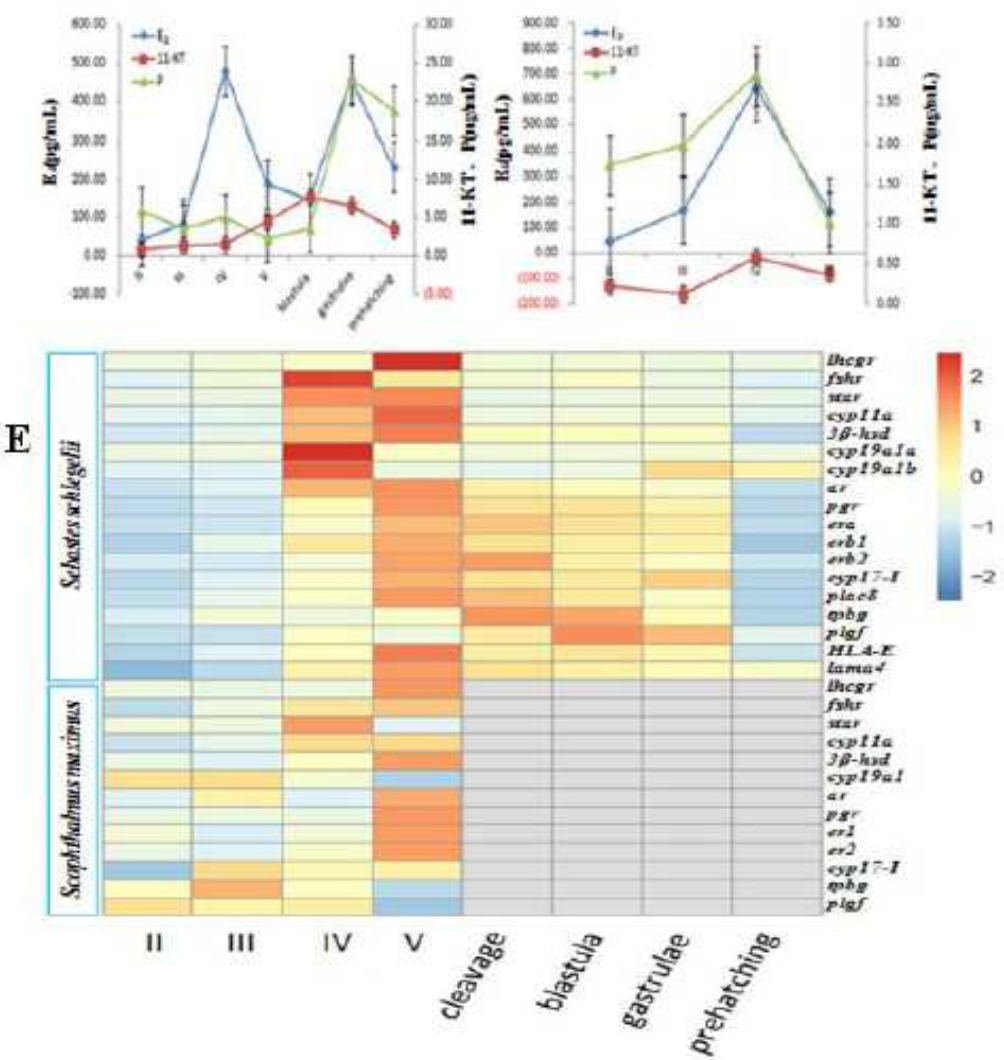

Figure 3

The changes of hormone level and related genes expression during the process of the ovarian development. A. Two-cell type model illustrates the Interaction of granulosa layers and theca cells of the ovarian follicle in the biosynthesis of active steroid hormones in gonad. Enzymes: P450scc (CYP11A1), P450 side-chain cleavage; P450c17(CYP17), 17-hydroxylase/C17-C20-lyase; 3b-HSD, 3b-hydroxysteroid dehydrogenase;17b-HSD, 17b-hydroxysteroid dehydrogenase; 20b-HSD, 20b-hydroxysteroid dehydrogenase; P450arom (CYP19A), P450 aromatase. B. Three steroid hormone changes during the oogenesis and placentation of black rockfish. 11-KT had been at a low level until the ovary developed to stage IV. When the ovary developed to stage IV, 11هKT level gradually rose and peaked at blastula stage. After that, it decreased slightly but still remained at a relatively high level throughout the pregnancy. The level of E2 increased significantly from stage III to stage V, and decreased at blastula stage. During pregnancy, E2 also maintained a high level, and peaked again during the gastrulae period. The level of $\mathrm{P}$ was low until blastula stage, it rapidly rose and remained a high level during the pregnancy period. C. Three steroid hormone changes during the oogenesis of turbot. The 11-KT, E2 and P level presented an upward trend囚peaked stage IV and decreased from stage IV to stage V. D. The results of two-color fluorescence in situ hybridization of cyp17-I and cyp19a1a at SGf and blastula. The expression of cyp17-I with green and cyp19a1a with red at SGf of black rockfish (a1-a3). the expression of cyp17-I with green and cyp19a1a with red in blastula stage of black rockfish (b1-b3). E. Expression profile of some important genes during ovarian development at eight different development stages. The log ratio 
expression is indicated in a heat map. 11-KT, 11『ketotestosterone; E2, 17ß-estradiol; P, progesterone; TC, theca cells; GC, granulosa cells; Y, yolk granules; FP, follicular placenta.

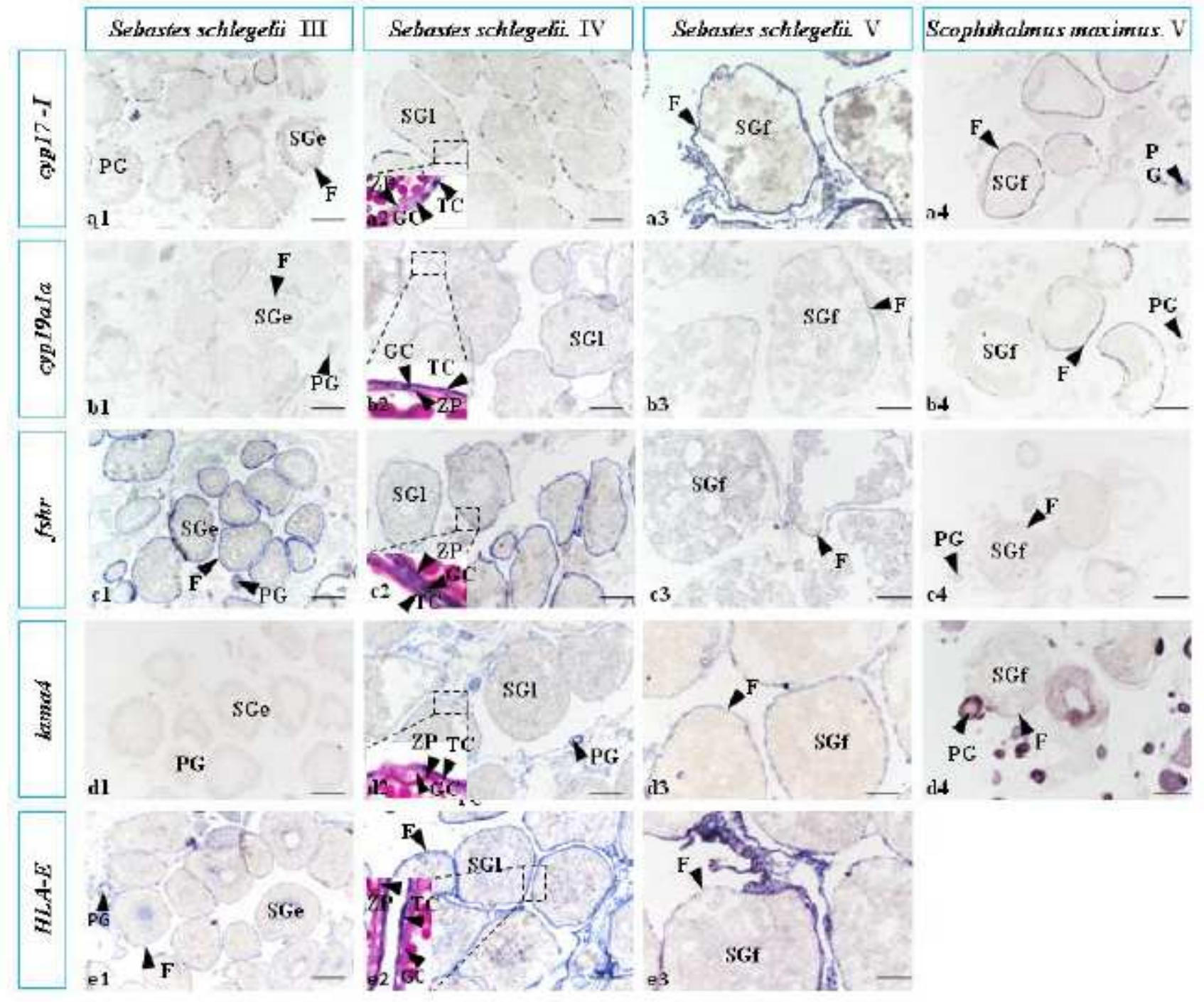

\section{Figure 4}

The expression of cyp17-I, cyp19a1a, fshr, lama4 and HLA-E in gonad during the oogenesis. At SGe stage, cyp17-I expressed on theca cells, and the signals gradually increased with the ovary development. At SGf stage, the signals of cyp17-I could be detected not only on theca cells, but throughout all the stromal cells around the oocytes, especially in stalk-like tissues (a1-a3). For turbot \cyp17-I only expressed on theca cells, not on the stromal cells around the oocytes at SGf stage (a4). Cyp19a1a only expressed on granulosa cells, and the signals got stronger significantly from SGe to SGI stages, and became weak at SGf stage (b1-b3). For turbot, the signals of cyp19a1a expressed on granulosa cells (b4). Fshr only expressed on granulosa cells, and the signals got stronger significantly from SGe to SGI stage, but the signals became very weak at SGf stage in black rockfish (c1-c3). For turbot, the signals of fshr expressed on granulosa cells (c4). Lama4 signals could not be detected on theca cells until the oocytes developed to SGI stage, and significantly increased at SGf stage on theca cells as well as the stromal cells around the oocytes in black rockfish (d1-d3). For turbot, Lama4 had no signal at SGf stage (d4). HLA-E signals 
could be detected on theca cells and stromal cells from SGe stage, and significantly increased at SGf stage (e1-e3). TC, theca cells; GC, granulosa cells; PG, follicles with primary growth; ZP, zona pellucida; SGe, early secondary growth; SGI, late secondary growth; SGf, full secondary growth; F, follicle layers. Scale bars, $200 \mu \mathrm{m}$.

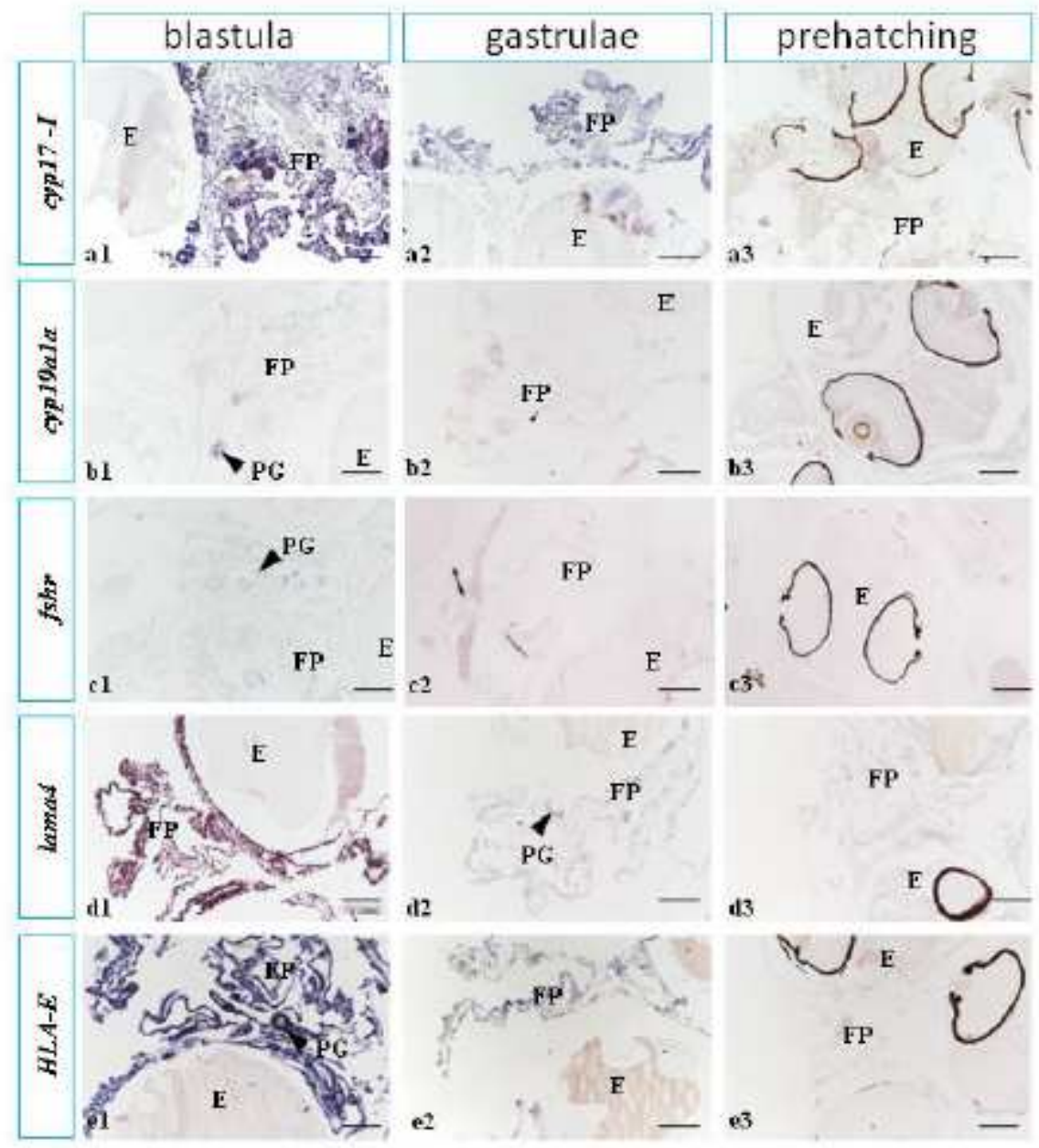

\section{Figure 5}

The expression of cyp17-I, cyp19a1a, fshr, lama4 and HLA-E during pregnancy. Cyp17-I signals presented strong on the follicular placenta at blastula and gastrulae stage, and disappeared at prehatching stage (a1-a3). Cyp19a1a had no obvious signals during pregnancy (b1-b3). The expression of fshr during the gestation of black rockfish. Fshr had no obvious signals during gestation (c1-c3). Lama4 expressed on the follicular placenta during the whole pregnancy period, the signals were strong at blastula and gastrulae stage, and became weak in the prehatching stage (d1-d3). HLA-E signals presented strong on the follicular placenta at blastula and gastrulae stage, and disappeared at prehatching stage (e1-e3). PG, follicles with primary growth; FP, follicular placenta; E, embryos. Scale bars, $200 \mu m$. 


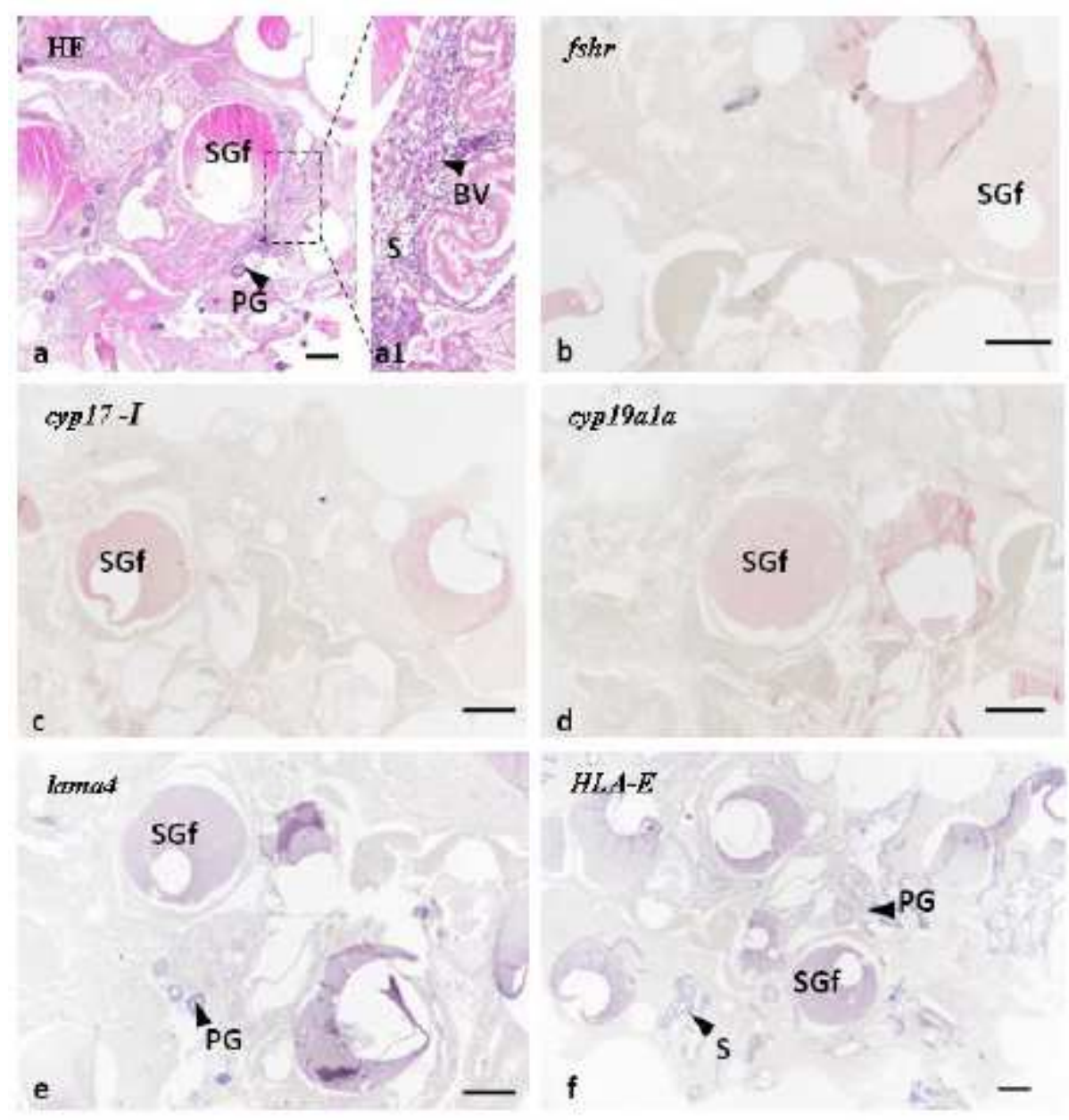

\section{Figure 6}

The morphogy and cyp17-I, cyp19a1a, fshr, lama4 and HLA-E localization in the isolated female black rockfish ovary. No obvious follicular placenta structure was observed in the ovary, and only stromal cells, vascular structure and non-cellular structure around the unfertilized eggs (a). Fshr, cyp17-I, and lama4 was not expressed on connection tissues around the oocytes (b-e), except HLA-E (f). PG, follicles with primary growth; SGf, full secondary growth; S, stromal cells; BV, blood vessel. Scale bars, $200 \mu \mathrm{m}$. 


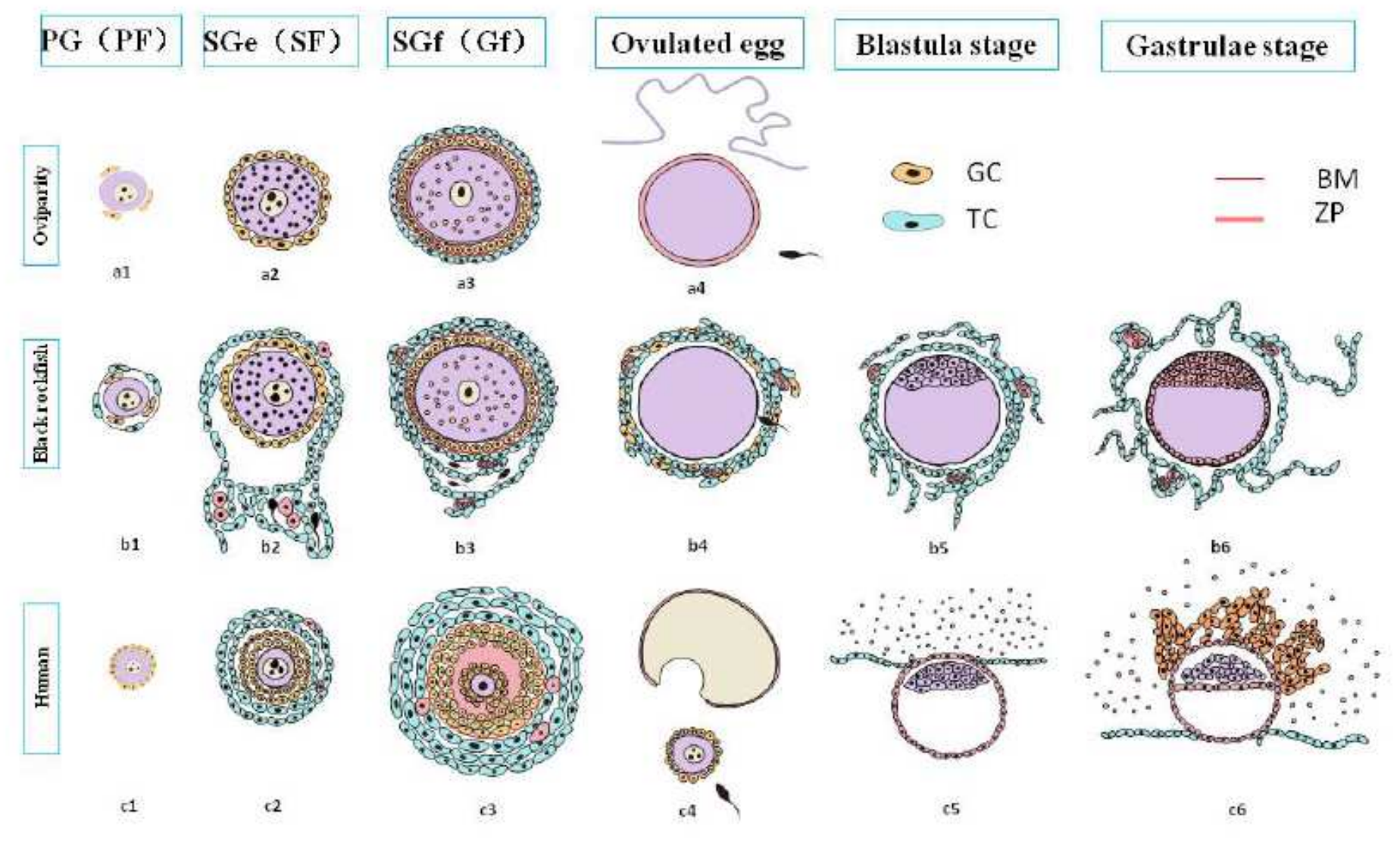

Figure 7

Cartoon illustrating the morphological difference during oogenesis and placentation among turbot (oviparity), black rockfish and human. Oogenesis and ovulation in turbot(oviparity) (a). After the follicles mature, the eggs are ovulated and fertilized in the water (a4). Oogenesis and placentation in black rockfish (b). After the follicles mature, the follicle layers rupture while the spermatozoa enter the micropyle (b4), then theca cells rapidly proliferate, migrate and invade outward forming the placenta (b5, b6). Oogenesis and placentation in human (c). After the follicles mature, the eggs are ovulated from the ovary to the fallopian tubes (c4), the sperm and egg unite to form a zygote (c5). Then the zygote travels down the fallopian tube and reaches the uterus. The morula becomes a blastocyst and implant into the uterine (c5, c6). PG, follicles with primary growth; SGe, early secondary growth; SGf, full secondary growth; PF, primary follicle; SF, secondary follicle; GF, graafian follicle; TC, theca cells; GC, granulosa cells; $\mathrm{BM}$, basement membrane; ZP, zona pellucida. 